\title{
Perspective
}

PERSPECTIVE Actualité en histoire de l'art

\section{2 | 2017}

\section{Le Maghreb}

\section{Les corans de l'Occident musulman médiéval : état des recherches et nouvelles perspectives}

The Korans of the Medieval Muslim West: Current Research and New

Perspectives

Die Korane des muslimischen Westens im Mittelalter: Forschungsstand und neue Perspektiven

I corani dell'Occidente musulmano medievale: stato delle ricerche e nuove prospettive

Los coranes del Occidente musulmán medieval: estado de las investigaciones y nuevas perspectivas

\section{Nourane Ben Azzouna}

\section{(2) OpenEdition}

\section{Journals}

Édition électronique

URL : http://journals.openedition.org/perspective/7574

DOI : $10.4000 /$ perspective. 7574

ISSN : 2269-7721

Éditeur

Institut national d'histoire de l'art

\section{Édition imprimée}

Date de publication : 31 décembre 2017

Pagination : 103-130

ISBN : 9782917902394

ISSN : $1777-7852$

Référence électronique

Nourane Ben Azzouna, «Les corans de l'Occident musulman médiéval : état des recherches et nouvelles perspectives », Perspective [En ligne], 2 | 2017, mis en ligne le 30 juin 2018, consulté le 01 octobre 2020. URL : http://journals.openedition.org/perspective/7574 ; DOI : https://doi.org/10.4000/ perspective.7574 


\section{Les corans de l'Occident musulman médiéval : état des recherches et nouvelles perspectives}

Le Coran, le livre sacré des musulmans, commence à être consigné par écrit du vivant du prophète Muhammad et diffusé au moyen de copies manuscrites par son troisième successeur, le calife 'Uthmān (r. 644-655) ${ }^{1}$. Si l'on estime le nombre de manuscrits en caractères arabes conservés à environ deux et demi à trois millions², il est difficile d'avancer des chiffres précis sur les manuscrits coraniques (muṣhaf, pl. maṣāhif). Ils sont indubitablement très nombreux, à commencer par des centaines de milliers de feuillets anciens ${ }^{3}$ et vraisemblablement des dizaines de milliers, ou du moins des milliers de volumes couvrant toute la durée de l'histoire arabo-islamique des origines jusqu'au présent.

Alors que la tradition des recherches sur le texte coranique est très ancienne et féconde, aussi bien dans le monde musulman qu'en "Occident ", l'intérêt pour les manuscrits coraniques est, quant à lui, beaucoup plus récent. Certes, ces manuscrits apparaissent dans les catalogues de manuscrits arabes dès le XVIII e siècle, et dans les albums de paléographie arabe à partir du milieu du XIX ${ }^{\mathrm{e}}$ siècle, mais on ne commence à les étudier de manière plus détaillée qu'au XX $X^{\mathrm{e}}$ siècle et surtout à la fin de ce siècle. Pourtant, leur étude ouvre des perspectives très prometteuses dans de nombreux domaines de l'histoire religieuse, sociale et culturelle arabo-islamique, de l'histoire de la transmission du texte coranique à celle de la lecture, du livre ou de la calligraphie en caractères arabes. Cet article s'intéressera plus particulièrement aux manuscrits coraniques de l'Occident musulman compris dans son sens le plus large : Maghreb, Sicile et Andalousie et surtout à l'époque médiévale. Il présentera les collections historiques les plus importantes, puis proposera un état des lieux sur les recherches les plus récentes, ainsi que sur les chantiers et les questions qui attendent les chercheurs à l'avenir.

\section{Collections, catalogues et outils de recherche}

Parmi les plus anciens fonds de manuscrits arabes conservés, plusieurs proviennent de l'Occident musulman et plus particulièrement du Maghreb. Le premier et le plus important est celui de Kairouan, la première capitale islamique et la citadelle du sunnisme dans le Maghreb médiéval. Le fonds de la Grande Mosquée de Kairouan, qui était conservé dans

\footnotetext{
Nourane Ben Azzouna est maître de conférences en histoire de l'art à l'université de Strasbourg. Elle est à la fois historienne de l'art, codicologue et paléographe spécialiste des manuscrits en caractères arabes médiévaux. Elle a surtout travaillé sur les manuscrits du Moyen-Orient (en arabe et en persan), mais elle s'est récemment tournée vers le Maghreb et en particulier la Tunisie où elle conduit plusieurs projets, notamment en partenariat avec la Bibliothèque nationale de Tunisie.
} 
l'enceinte réservée au souverain (maqșūra) des Aghlabides, date vraisemblablement du III ${ }^{\text {/ }}$ IX $\mathrm{X}^{\mathrm{e}}$ siècle ${ }^{4}$. Il est documenté par un inventaire médiéval établi en 693 de l'hégire (c'est-à-dire en 1294) qui mentionne environ cent-cinquante manuscrits dont une majorité de corans et d'ouvrages de droit (figh) malikite (respectivement 90 et 45 items). Enrichi au fil du temps, ce fonds compte aujourd'hui quelques 39000 feuillets et 8000 volumes, toujours principalement coraniques et de droit malikite ${ }^{5}$.

Parallèlement au fonds de Kairouan, d'autres collections historiques sont encore au moins en partie conservées. L'une des plus importantes est celle de la bibliothèque des Kairouanais, Qarawiyyīn, à Fès, qui a été fondée par le souverain mérinide Abū 'Inān en 750/1349 et enrichie par ses successeurs, puis par le dépôt d'autres collections fassies au $\mathrm{XX}^{\mathrm{e}}$ siècle $^{6}$ (plusieurs milliers de feuillets et plus de 2000 volumes). Mais nous pouvons aussi mentionner plusieurs autres bibliothèques rattachées à des grandes mosquées ou d'autres institutions religieuses (écoles supérieures [madrasa], hospices [zāwiya], mausolées...), comme la Grande Mosquée Zaytūna ou Zītūna de Tunis ; la mosquée Benyoussef de Marrakech ; la Grande Mosquée de Taza, etc. ${ }^{7}$.

Aujourd'hui, la situation de ces collections diffère d'un pays du Maghreb à l'autre. Alors qu'au Maroc, la majorité des manuscrits sont encore conservés là ils ont été constitués biens de mainmorte (on emploie le terme de waqf en Orient et de habūs en Occident musulman), en Algérie, la colonisation française et le choix de l'assimilation territoriale et culturelle ont conduit à la destruction d'une grande partie du patrimoine écrit, des archives et des manuscrits (par exemple, pour ne citer que quelques cas emblématiques, les archives de la Qașba d'Alger en 1830 ou la bibliothèque de l'émir Abdelkader en 1843). Des bribes de fonds anciens ont été conservées in situ, dans des mosquées, des madrasas, des zāwiyas et surtout dans des collections privées. D'autres ont été regroupées au sein de la Bibliothèque nationale qui continue à en acquérir, mais ne compte aujourd'hui que quelques 4000 manuscrits. Depuis l'indépendance, et surtout depuis les années 1990, des projets de recensement, de collecte, de conservation, de restauration et d'étude sont menés dans plusieurs régions du pays, en particulier à Adrar, mais ils se heurtent à de nombreuses difficultés, parfois inattendues, comme par exemple la place du patrimoine arabe en terre berbère ou encore la légitimité des doctrines religieuses locales dans un contexte plus globalisé ${ }^{8}$. En Tunisie, après l'indépendance, et à l'exception du fonds de Kairouan qui est encore largement conservé dans cette ville (au Musée national d'art islamique de Raqqāda-Kairouan), la plupart des collections ont été réunies au sein de la Bibliothèque nationale de Tunisie en 1967-1969. Cette bibliothèque s'est ensuite enrichie de dons et de legs divers pour devenir la plus grande bibliothèque de manuscrits du Maghreb, conservant environ 25000 volumes et 40000 titres?.

En Espagne, la Reconquista, l'expulsion et la répression des musulmans et la destruction de leurs livres ont abouti à la disparition de la plupart des fonds anciens comme, pour ne citer qu'un exemple célèbre, la bibliothèque du calife umayyade de Cordoue, al-Ḥakam II (r. 961-976) ${ }^{10}$. Cependant, une collection historique, celle des souverains saadiens, fut saisie par des pirates espagnols, avant d'être offerte à Philippe III d'Espagne qui la déposa à la bibliothèque royale à l'Escorial en $1612^{11}$. De plus, les communautés musulmanes restées en Espagne, les Mudéjars (jusqu'en 1502) et les Morisques (à partir de 1502) ont continué à produire des manuscrits, comme en témoignent quelques centaines d'exemplaires, dont des corans et des traductions du Coran, retrouvés dans diverses caches ${ }^{12}$. Enfin, parallèlement aux collections et aux bibliothèques anciennes, de nombreuses bibliothèques plus récentes conservent des manuscrits, notamment des corans de l'Occident musulman, aussi bien au Maghreb (la Bibliothèque nationale du Royaume du Maroc [BNRM], la Bibliothèque royale à Rabat, plusieurs bibliothèques universitaires au Maroc et en Algérie...) que dans le reste du monde ${ }^{13}$. 
Malgré son caractère exceptionnel, le fonds de Kairouan est à mon sens emblématique des problèmes, voire des dangers qui pèsent sur les collections de manuscrits dans de nombreux pays du monde arabo-musulman et du Maghreb. En effet, ce fonds n'est ni catalogué, ni même proprement conservé, surtout depuis la révolution de 2011 : en six ans, quatre directeurs se sont succédés à la tête du Musée national d'art islamique de Raqqāda. Dans un tel contexte, cette collection est non seulement peu connue, peu étudiée, et d'ailleurs difficilement accessible, mais elle est aussi en danger. En effet, des feuillets provenant de manuscrits kairouanais, comme le fameux Coran bleu ou le célèbre Coran de la Nourrice (muṣhafal-hạdina) apparaissent régulièrement dans les ventes d'objets d'arts de l'Islam, et sont acquis sans état d'âme par des institutions culturelles prestigieuses et des collectionneurs privés ${ }^{14}$. Et des menaces similaires pèsent sur de nombreux autres fonds, par exemple au Maroc ${ }^{15}$. On ne saurait donc assez insister sur l'urgence de publier les catalogues des collections de manuscrits, aussi bien anciennes, comme celle de Kairouan, que récentes, comme celle de la Bibliothèque nationale de Tunisie, où seuls les 10000 premiers volumes, autrement dit moins de la moitié, sont catalogués ${ }^{16}$. En effet, sans ce travail, ces collections sont non seulement peu connues et peu exploitées, mais aussi offertes au pillage. Les catalogues, imprimés et/ou numériques, et les numérisations, permettraient notamment de pouvoir prouver la provenance des feuillets et des volumes dérobés et d'engager des procédures de restitution, mais aussi de limiter les possibilités de ventes, au moins publiques.

La mise à jour des catalogues existants est aussi un autre chantier important. Dans un article récent, Juan Pablo Arias Torres et François Déroche ont proposé quelques réflexions sur le catalogage des manuscrits coraniques, notamment de l'Occident musulman ${ }^{17}$, plaidant pour un relevé aussi complet et aussi détaillé que possible de toutes les données textuelles et caractéristiques techniques et formelles de ces manuscrits en vue de constituer des corpus d'informations qui peuvent être pertinentes pour divers sujets. Les auteurs se sont livrés eux-mêmes à l'expérience en relevant les titres des sourates - " détail » rarement mentionnés dans les catalogues - dans un échantillon de corans hispano-maghrébins. Cette recherche a révélé des variantes qui pourraient renvoyer à une ou des transmissions du texte coranique spécifiques à la péninsule ibérique ${ }^{18}$. Arias Torres et Déroche ont aussi suggéré de faire des observations similaires sur le nombre de versets indiqué pour chaque sourate, les prosternations rituelles (sajda), ou les lectures canoniques ( $q$ ir $\bar{a} \mathbf{a} t)$, afin de déterminer si certaines tendances peuvent être associées à des régions, des écoles juridiques ou des époques précises.

À ce titre, il faut certainement tirer profit d'un outil développé par Teresa Espejo et Ana Beny : un «protocole pour la description des manuscrits andalous ${ }^{19}$ ". Ce dernier permet de mettre en valeur certaines particularités textuelles, mais aussi codicologiques et paléographiques propres aux manuscrits, notamment coraniques andalous, mais qui sont aussi pertinentes pour l'Occident musulman dans son ensemble. Parmi ces particularités figure le "zigzag " : une marque formée d'une série de lignes claires obtenues par enlèvement de copeaux à l'aide d'un instrument tranchant à différents endroits de la feuille de papier séchée. Sa fonction est probablement purement mécanique. Selon l'un des plus grands spécialistes de l'histoire du papier, Jean-Louis Estève, le zigzag « facilite le pliage des feuilles, [...] tempère le phénomène de chasse et réduit la fluctuation des marges pour améliorer ce que les imprimeurs appellent le "registre" ; il permet à l'ouvrage relié d'être proche du parallélépipède ${ }^{20}$ ". Or, le zigzag n'apparaît que dans les papiers de l'Occident musulman (et des papiers filigranés italiens) et uniquement du XII ${ }^{\mathrm{e}}$ au XIV ${ }^{\mathrm{e}}$ siècle $^{21}$. À cela s'ajoute une disposition particulière des vergeures qui sont le plus souvent réparties de manière symétrique de part et d'autre du pli de la double page (qui correspond généralement à l'axe de la forme). Selon les termes d'Estève, " les traces laissées par les vergeures dans les marges de grand-fond sont plus irrégulières et d'un diamètre supérieur à celles laissées dans les marges de petit-fond ${ }^{22}$ ". Cela s'explique par l'emploi de vergeures végétales (palmes?), non pas cylindriques mais coniques, 
qui s'affinent de la base au sommet et qui sont donc placées tête-bêche afin d'obtenir une forme régulière ${ }^{23}$. Les écritures dites " maghrébines " (Maghribī) sont une autre spécificité des manuscrits, notamment coraniques hispano-maghrébins (infra) ${ }^{24}$.

Le protocole d'Espejo et Beny est assez rare pour être signalé. En effet, les recherches aussi bien sur les manuscrits arabes, les manuscrits coraniques et les corans hispano-maghrébins souffrent d'un manque abyssal d'outils de recherche transversaux. L'un des seuls outils disponibles est le FiMMOD, le Fichier des manuscrits du Moyen-Orient datés, qui, comme son nom l'indique, ne concerne pas prioritairement l'Occident musulman ${ }^{25}$. Mustapha Jaouhari mène, depuis 2011, une vaste enquête sur les manuscrits en écritures Maghribī datés, et Nuria Martínez de Castilla, depuis 2013, le projet Corana, Production et transmission du Coran dans l'Occident musulman qui vise à créer une base de données des corans hispano-maghrébins du $\mathrm{XII}^{\mathrm{e}}$ au XVII ${ }^{\mathrm{e}}$ siècle, mais ces deux projets n'ont pas encore tout à fait abouti ${ }^{26}$. En attendant, les chercheurs ne disposent pas, par exemple, d'un fichier des copistes, des lecteurs ou des possesseurs. Un instrument récent, Islamic Seals Database ${ }^{27}$ est, certes, bien utile pour qui tente de reconstituer la circulation des manuscrits et l'histoire des collections, mais il ne permet pas d'effectuer de recherche par lieu. Créer ou parachever ces outils de travail, de manière à permettre des recherches si ce n'est systématiques, du moins quantitativement et qualitativement significatives sur plusieurs aspects de l'histoire des manuscrits arabes, coraniques et hispano-maghrébins, serait donc un autre chantier colossal à mener.

À ce titre, il faut signaler que quelques projets d'informatisation et de numérisation à plus ou moins grande échelle sont en cours. Ainsi, un projet intitulé « Les Trésors manuscrits au Royaume du Maroc " (Dhakhā'ir al-makhtụtāt bi'l-mamlaka al-maghribìyya) est mené depuis une quinzaine d'années par la BNRM, le ministère de la Culture marocain et l'UNESCO, afin d'informatiser les inventaires et les catalogues de manuscrits existants et de numériser totalement ou partiellement quelques manuscrits dans plusieurs fonds du pays ${ }^{28}$ (Qarawiyyīn, Benyoussef, Grande Mosquée de Meknès...). Ces bases de données et manuscrits numérisés ne sont cependant accessibles que dans les institutions correspondantes et ne sont pas publiés en ligne. Le projet de Mustapha Jaouhari sur les manuscrits en écritures Maghribī datés inclut, quant à lui, davantage de fonds (outre les trois collections du projet précédent, la BNRM, la Bibliothèque royale, la bibliothèque Gannoun de Tanger, les Grandes Mosquées de Wazzān et Taza et la zāwiya al-Ḥamziyya). De plus, il vise la mise en ligne des volumes ${ }^{29}$ (sur le site du Centre Jacques Berque [CJB], Rabat). De même, l'association RIF tente de numériser les manuscrits des bibliothèques privées du Maroc, mais non sans rencontrer de difficultés ${ }^{30}$. À la Bibliothèque nationale de Tunisie, bien que seuls les catalogues des manuscrits $\mathrm{n}^{\text {os }} 1$ à 9999 soient publiés, les 40000 titres de la collection sont accessibles via une base de données consultable sur place et quelques manuscrits sont numérisés ou peuvent l'être à la demande. De plus, la Bibliothèque vient de s'engager, en 2016, dans un vaste projet de numérisation intégrale de ses fonds manuscrits. Il va sans dire que ces projets ouvrent de nouvelles possibilités pour la recherche, notamment la recherche sur les volumes du Coran, comme le démontrent par exemple les cinq journées d'études organisées par Mustapha Jaouhari depuis $2012^{31}$.

\section{Les premiers corans de l'Occident musulman : \\ les corans " coufiques occidentaux " ou \\ " coufiques maghrébins", des origines au XI ${ }^{e}$ siècle}

Durant le dernier tiers du $\mathrm{XX}^{\mathrm{e}}$ siècle, la paléographie arabe, et en particulier celle appliquée aux corans, a connu une révolution méthodologique. Alors que, jusque-là, les recherches sur le Coran, mais aussi sur l'histoire du livre ou l'histoire de la calligraphie en alphabet 
arabe étaient essentiellement basées sur les sources textuelles arabes, quelques chercheurs, au premier rang desquels François Déroche, ont mis en avant les manuscrits comme objets religieux et socio-culturels signifiants en eux-mêmes en tant qu'ils étaient montrés, lus, étudiés et transmis. Ce sont donc des sources de premier plan qui peuvent apporter un éclairage nouveau, voire permettre de reconsidérer radicalement de nombreuses questions d'histoire religieuse, intellectuelle, sociale ou culturelle. Ainsi, Déroche a révolutionné la perception même des manuscrits coraniques en remettant à plat toutes les classifications antérieures, largement héritées des sources historiques arabes ( Hiijāzī », " coufique ", etc.), et en reprenant le sujet à zéro en se basant sur l'étude codicologique et paléographique détaillée des spécimens conservés.

Si Déroche a reconnu la validité de la catégorie « Hijāzīi " proposée par Michele Amari au milieu du XIX ${ }^{e}$ siècle pour désigner les fragments coraniques les plus anciens, datables du VII ${ }^{\mathrm{a}}$ au début du VIII ${ }^{\mathrm{e}}$ siècle, qui se distinguent par un certain nombre de caractéristiques codicologiques, orthographiques et paléographiques, notamment un alif incliné à droite ${ }^{32}$, il a appelé à abandonner le terme " coufique " qui ne fait qu' « obscurcir le débat et fausser les analyses $^{33}$ " parce que ses " liens avec le matériel étudié [sont] manifestement impossibles à établir ${ }^{34}$ ». En lieu et place du « coufique », Déroche a proposé de parler d" " écritures abbassides anciennes $^{35}$ ». Ses successeurs, comme Alain George par exemple, ont préféré cependant conserver l'usage du terme " coufique " pour ces graphies qui, d'une part, commencent à se développer sous la dynastie umayyade (661-750), avant la prise du pouvoir par les Abbassides en 750, et, d'autre part, et selon les termes mêmes de Déroche, «frappent [...] par la constance et la régularité du trait rectiligne employé pour tracer les lettres, qu'il s'agisse des verticales ou des horizontales ${ }^{36}$ ", autrement dit ces graphies angulaires ou pseudo-angulaires qui dominent dans les manuscrits coraniques du VIII ${ }^{e}$ au $\mathrm{X}^{\mathrm{e}}$ siècle. Cependant, le différend terminologique ne diminue en rien la pertinence des observations paléographiques de Déroche qui a mis en évidence, aussi bien au sein du " Hijāāī » que du " coufique " et de son successeur, le "Nouveau Style " (NS), une grande variété de "familles" (Hijāzī A, B, C, D, E, F, NS) et de " types » ou de "styles » (Hijāzī I, II, III, IV ; A. I ; B. I, II...), auxquels s'ajoute la diversité des " écritures livresques non coraniques".

L'un des grands reproches exprimés contre la typologie de Déroche est son caractère perméable - les éléments d'un groupe se retrouvent dans d'autres groupes, les variantes sont donc très nombreuses - mais aussi son abstraction qui ne permet pas de lier la majorité des familles ou des styles à des lieux ou des contextes historiques déterminés, faute de colophons et d'autres indications historiques suffisamment précises durant les trois premiers siècles de l'Islam ${ }^{37}$. Ainsi, si le Hijāzī semble s'être diffusé au-delà de la région du Hijāāz, mais peut-être pas jusqu'au Maghreb où aucun fragment n'a été retrouvé, même à Kairouan ${ }^{38}$, il paraît impossible ou du moins extrêmement difficile de distinguer entre les corans coufiques réalisés en Iraq, en Syrie, en Égypte ou au Maghreb en se basant sur des critères codicologiques et paléographiques seuls, et ce même pour les manuscrits liés à des fonds historiques comme celui de Kairouan, d'autant plus que « des corans en écriture abbasside ancienne pourraient avoir circulé assez tôt ${ }^{39}$ ".

Prenons l'exemple du Coran bleu qui est reconnu, à juste titre, comme l'un des chefsd'œuvre des débuts de l'Islam ${ }^{40}$ (fig. 1). Il s'agit du seul coran sur parchemin bleu connu qui soit parvenu jusqu'à nous ${ }^{41}$. Originairement composé d'environ six cent feuillets, seule une centaine de feuillets est aujourd'hui conservée, principalement à Raqqāda, mais de nombreuses pages sont dispersées dans diverses collections dans le monde. De format oblong, à l'italienne, et de taille importante (max. $31 \times 41 \mathrm{~cm})$, il est écrit à raison de quinze lignes par page, au moyen d'une technique de chrysographie unique. En effet, le calligraphe n'a pas utilisé une encre dorée, mais il a tracé tout le texte à l'aide d'une substance adhésive transparente ; 


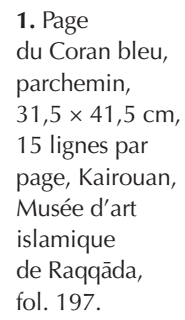

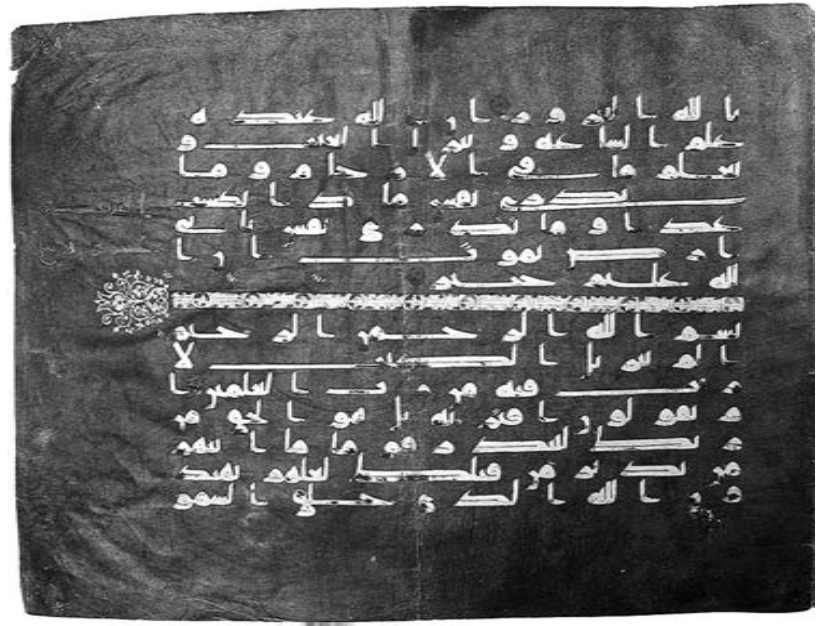

puis il a appliqué de la feuille d'or, éliminé l'excédent d'or, bruni et enfin tracé des contours à l'encre brune. Les dimensions du support et de l'écriture, les matériaux, la technique en font une ouvre fastueuse, plus somptueuse encore que les bibles pourpres écrites à l'encre d'argent de l'Empire byzantin. La calligraphie correspond au style D. IV de Déroche. Le manuscrit est aussi enluminé, avec des bandeaux dorés entre les sourates, des rosettes entre les versets et des lettres à valeur numérique (abjad) entre les groupes de cinq et dix versets ${ }^{42}$. Cet unicum a fait couler beaucoup d'encre et a été attribué à des contextes aussi éloignés que l'Iran oriental (Machhad) ${ }^{43}$, l'Iraq abbasside (Bagdad ou Samarra) ${ }^{44}$, la Tunisie aghlabide (sunnite) ou fatimide (chiite) ${ }^{45}$, la Sicile aghlabide ou kalbide ${ }^{46}$, et l'Andalousie umayyade ${ }^{47}$. Si les recherches les plus récentes (GEORGE, 2010b) ont permis d'affiner sa datation vers la seconde moitié du VIII ${ }^{\mathrm{e}}$ ou la première moitié du IX siècle, la question de sa provenance, en particulier entre l'Orient et l'Occident musulmans, reste en revanche difficile à trancher.

Le premier coran daté de la collection de Kairouan peut fournir un autre exemple des difficultés à dater et à identifier les lieux de production des premiers manuscrits coraniques qui nous sont parvenus. Il s'agit d'un coran en trente volumes, de format oblong, de dimensions plus réduites $(10 \times 16,5 \mathrm{~cm})$, mais écrit de manière plus espacée, à raison de six lignes par page, en D. III, et richement enluminé. Comme indiqué par l'acte de donation autographe écrit au début de chaque trentième (juz'), ce manuscrit a été constitué bien de mainmorte (habasat) par une certaine Faḍl, affranchie (mawlāt) de feu Abū Ayyūb Aḥmad b. Muḥammad, à la Grande Mosquée de Kairouan au mois de Muharram 295/octobre-novembre $907^{48}$. Ce manuscrit est souvent considéré comme un coran coufique kairouanais. Cependant, le parchemin a été daté au carbone 14, avec $95 \%$ de certitude, entre 716 et 891 . Son exécution est donc antérieure, au moins d'une quinzaine d'années, à son dépôt à Kairouan. Comme pour le Coran bleu, et comme George l'a noté, le fait qu'il ait été déposé à Kairouan ne signifie pas qu'il a été produit dans cette ville. Il a en effet pu être réalisé ailleurs, par exemple plus à l'Est, avant d'être acheminé vers la capitale aghlabide. Deux autres corans de format oblong $(27,5 \times 37$ et $22,5 \times 32 \mathrm{~cm}$ ), écrits respectivement en D. I et D. III et datés par Déroche du IX siècle, posent des questions analogues. Ils ont en effet été offerts par des membres de la dynastie ziride, qui gouverne le Maghreb oriental ou Ifrīqiyya au nom des Fatimides (972-1148), au profit de la Grande Mosquée de Kairouan durant la première moitié du XI siècle. L'un a été constitué habūs par Umm Malāl (m. 414/1023), la tante et régente d'al-Mu 'izz b. Bādis, le quatrième prince ziride (r. 1016-1062) ${ }^{49}$; l'autre par al-Mu 'izz b. Bādis lui-même après sa rupture avec les Fatimides en $1049^{50}$. Ces corans posent non seulement la question du déplacement des manuscrits, mais aussi de la survie et de l'utilisation des codex et de leurs graphies longtemps après leur production, en particulier en Ifrīqiyya.

En revanche, à partir du dernier tiers du $\mathrm{X}^{\mathrm{e}}$ siècle, on possède à la fois des colophons et des certificats de commandes qui permettent d'identifier des corans indubitablement occidentaux. Le premier est probablement un fragment de coran de format oblong où une note 
d'une main et une encre différentes indique qu'il a été copié en Sicile, à Palerme (madīnat șiqilliyya), en $358 / 969^{51}$. Un autre coran de format oblong $(17,6 \times 25 \mathrm{~cm})$ contient, quant à lui, un colophon indiquant qu'il a été réalisé dans la même ville une quinzaine d'années plus tard, en 372/982-98352 (fig. 2). Si à cette époque la Sicile est sous domination fatimide, ce coran s'ouvre par un double-frontispice inscrit d'une déclaration sur la nature incréée du Coran (au fol. $\left.2 \mathrm{r}^{\circ}\right)$, notion incompatible avec l'idéologie mu tazilite adoptée et perpétuée par plusieurs communautés chiites, notamment les Fatimides, et qui suggère que le manuscrit a été produit par et pour une communauté sunnite, vraisemblablement sous l'influence de l'Ifrīqiyya malikite.

À côté de ces deux corans siciliens, on connaît plusieurs corans commandités par des femmes de la cour ziride au début du $\mathrm{XI}^{\mathrm{e}}$ siècle. C'est le cas du célèbre coran dit de la Nourrice (fig. 3) qui contient un colophon et un acte de habūs indiquant qu'il a été réalisé à la demande de Fātịma, la nourrice de Bādis, le père d'al-Mu 'izz, sous la supervision ('alā yaday) de Durra, la scribe (al-kātiba), et qu'il a été copié, vocalisé selon les règles coraniques, enluminé et relié (kataba, shakala, rasama, dhahhaba, jallada) par un certain 'Alī b. Aḥmad qui exerce la fonction de copiste, fabricant de parchemin, de papier ou de livres et/ou libraire (warrāq), avant d'être offert à la Grande Mosquée de Kairouan en Ramadan 410/janvier 102053. Il s'agit d'un coran en soixante volumes de format vertical, à la française, monumental (max. $46 \times 32 \mathrm{~cm}$ ), copié à raison de cinq lignes par page : l'ensemble devait compter environ 3200 feuillets de parchemin. Le coran donné par Umm al- 'Ulū, la sœur d'al-Mu 'izz, à la mosquée d'Abū 'Abd al-Muțalib à Bāb Salam à l'ouest de Kairouan en est un autre exemple ${ }^{54}$.

Curieusement, plusieurs de ces premiers corans occidentaux partagent des caractéristiques codicologiques, paléographiques et décoratives avec les corans orientaux. Ainsi les corans de Palerme et celui de la Nourrice sont-ils calligraphiés en NS, un style mi-angulaire mi-arrondi, qui se caractérise en outre par des pleins et des déliés très accentué ${ }^{55}$. La calligraphie monumentale et le système de vocalisation du Coran de la Nourrice ont été comparés à ceux d'un coran oblong exécuté à Ispahan en Ramadan 383/octobre-novembre $993^{56}$. Le Coran de la Nourrice se distingue en outre par son format vertical qui réapparaît dans

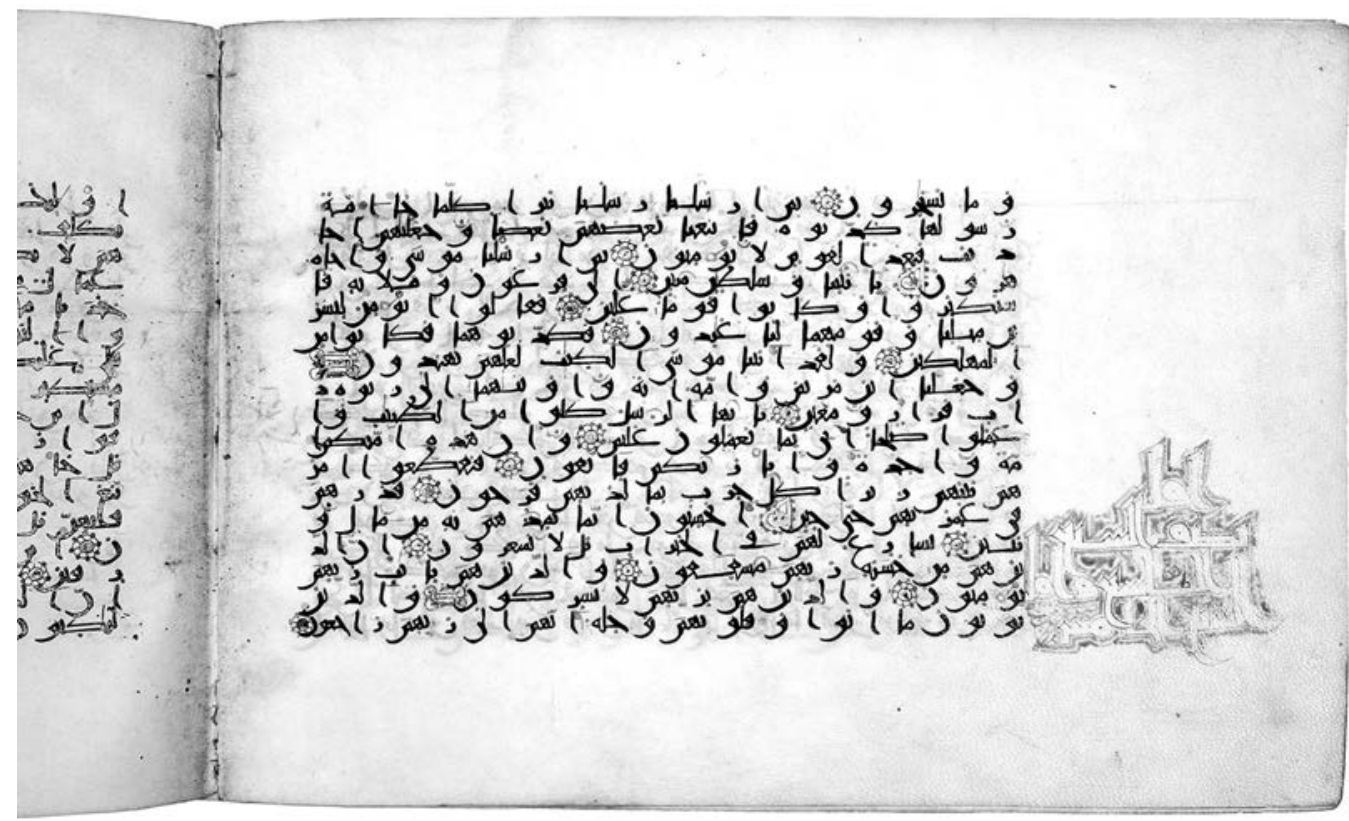

2. Page du Coran de Palerme, 372/982-983, parchemin, $17,6 \times 25 \mathrm{~cm}$, Londres, Collection Nasser D. Khalili, manuscrit QUR 261, fol. $8 \mathrm{~b}$. 
3. Page du Cora de la Nourrice, parchemin, $45 \times 31 \mathrm{~cm}$,

5 lignes par page, Kairouan, Musée national d'art islamique de Raqqāda, fol. 25.

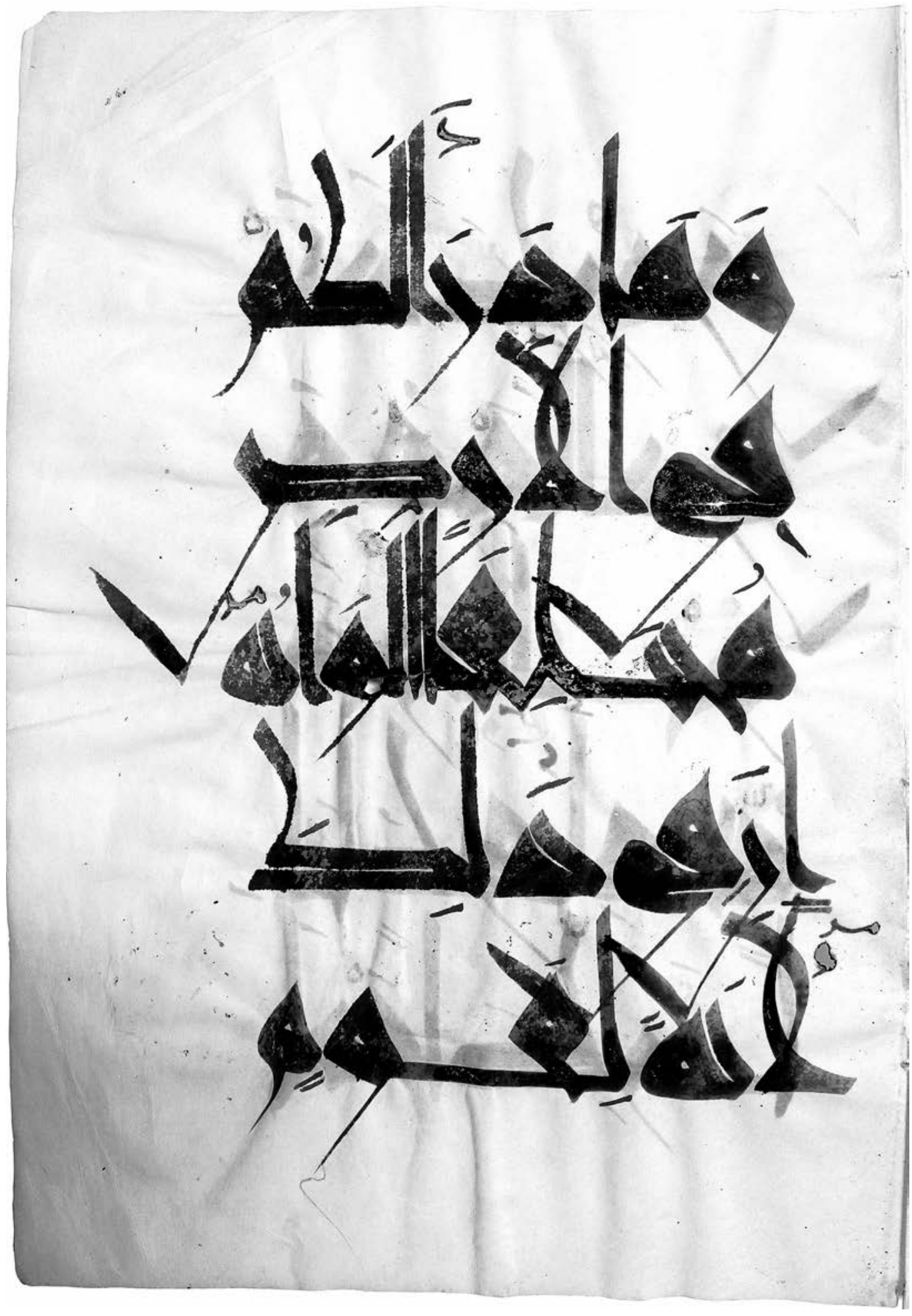




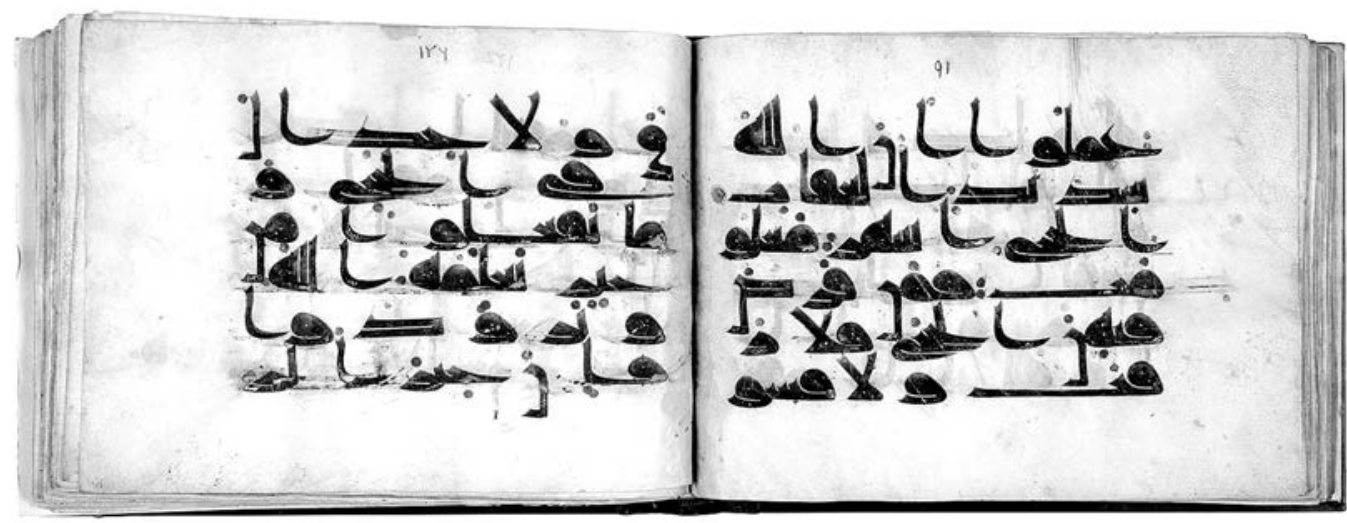

4. Double-page de Coran, parchemin, écriture D. II, Londres, Collection

Nasser D. Khalili, manuscrit QUR 372, fol. $47 \mathrm{~b}-48 \mathrm{a}$.

les corans orientaux au $\mathrm{X}^{\mathrm{e}}$ siècle. Son colophon et son acte de habüs sont tracés dans un " beautiful chancery script akin to the style of coeval Fatimid Egyptian decrees ${ }^{57}$ ". Le cinquième verset est marqué par un $h \bar{a}$ ' doré cerné de contours noirs. Ces observations soulèvent une question : en cas d'absence de colophon ou d'autre inscription historique, comment identifier les corans en coufique ou NS de l'Occident musulman aux $\mathrm{X}^{\mathrm{e}}-\mathrm{XI}^{\mathrm{e}}$ siècles ? Les chercheurs ont proposé plusieurs pistes pour les distinguer : le décor ; les points et autres signes (traits, cercles) de couleur rouge, jaune, verte ou bleue qui, du tournant des $\mathrm{VII}^{\mathrm{e}}-\mathrm{VIII}{ }^{\mathrm{e}}$ jusqu'au XI ${ }^{e}$ siècle, indiquent les voyelles, notamment les variantes de lecture (qirà $\left.\bar{a} t\right)$, et distinguent entre certaines consonnes homographes comme $f \bar{a}^{\prime}(\mathrm{F})$ et $q \bar{a} f(\mathrm{Q})$; ou encore le vocabulaire $^{58}$. Ainsi, en partant du décor du Coran de Palerme datant de 982-983, Déroche a établi un lien avec un autre coran de format oblong, écrit en D. II ${ }^{59}$ (fig. 4), puis avec un petit groupe de corans de même format et de même graphie (D. II) qui présentent des enluminures similaires, attribuant l'ensemble à une " école régionale " située dans le Maghreb oriental, Sicile et Ifrīqiyya, au X $\mathrm{x}^{\mathrm{e}}$ siècle $^{60}$.

Alain George, quant à lui, s'est tourné vers les points et autres signes colorés ${ }^{61}$. En confrontant les sources historiques sur le sujet, en particulier les écrits du savant andalou al-Dānī (982-1053), avec plusieurs manuscrits dont l'origine occidentale est certaine, comme le Coran de Palerme, ou supposée, comme le groupe D. II entre autres, il a pu mettre en évidence un certain nombre de spécificités de cette région. Ainsi, dit-il :

A Qur'an vocalised with red dots for vowels and tanwin but with yellow dots for hamza follows
Medinan conventions, and may have been produced in Medina, or possibly the early Maghrib;
additional signs in a thin red pen might have sometimes been used in Medina and the early
Maghrib. A Qur'an vocalised with red dots for vowels and tanwīn, yellow dots for hamza, a green
or blue dot and/or a red stroke for șila, and a red stroke or circle for sukün follows Maghribi
conventions, and may have been produced in the Maghrib [...]. The presumption of a Maghribi
origin may be reinforced by other features associated with this region by al-Dänī [...]; by the
notation of fä' and qäf with a single diacritical sign placed respectively below or above the letter ${ }^{62}$.

À cela s'ajoutent quelques particularismes de vocabulaire, comme l'utilisation du terme nabra au lieu de hamza ${ }^{63}$. Ces observations ont aussi permis au chercheur de sonder la diffusion de certains styles coufiques " conventionnels " ou "classiques " comme B. II, D. I, D. III ou D. IV, et les variantes apportées en particulier au groupe D dans l'Occident musulman, et de mettre ainsi en avant des particularités paléographiques et décoratives occidentales inédites, caractéristiques des $\mathrm{X}^{\mathrm{e}}-\mathrm{XI}^{\mathrm{e}}$ siècles. Par exemple, l'épaisseur des traits tend à s'accentuer et à s'uniformiser. L'indication du cinquième verset en forme de $h \bar{a}$ ' se termine fréquemment par une pointe supérieure en demi-palmette. La palette employée 
est souvent plus riche ${ }^{64}$. En même temps, les recherches de George ont révélé la grande diversité de la production attribuable à l'Occident musulman elle-même, ce qui est à mettre au compte des voyages et des contacts permanents entre les différentes régions du monde musulman.

Il faut ajouter enfin une remarque importante à propos du ou plus exactement des " coufiques maghrébins": ces styles, particulièrement associés aux manuscrits coraniques, ont, semble-t-il, été imités, du moins dans leur angularité, pour copier les textes fondateurs du malikisme ${ }^{65}$. De même que les manuscrits en Hijāzī semblent avoir été en usage au-delà du début du VIII ${ }^{\text {e }}$ siècle, comme le montrent plusieurs traces de ré-encrage, de corrections et d'additions, notamment de vocalisation, et comme, au Maghreb, des corans du IX ${ }^{\mathrm{e}}$ siècle ont été conservés et offerts par les Zirides à la Grande Mosquée de Kairouan durant la première moitié du $\mathrm{XI}^{\mathrm{e}}$ siècle, la transposition des " coufiques maghrébins » du Coran vers les ouvrages de référence du malikisme suggère qu'une valeur symbolique puissante, une forme de sacralité archétypale était attachée à ces graphies. Voilà qui explique leur continuité, voire leur revival, et permet de se demander si les quelques corans en NS, qui semblent très circonscrits dans l'espace - Maghreb oriental - et dans le temps - fin Xe/début XI siècle - ne peuvent pas être interprétés de manière analogue, comme portant une connotation positive, par exemple abbasside ou sunnite, forte. Au sein de ce corpus, quelques manuscrits se distinguent par l'association entre les caractéristiques du " coufique maghrébin " et celles des générations postérieures. Ainsi, dans un fragment coranique de format oblong $(14,4 \times 17,5 \mathrm{~cm})$ daté du 6 Șafar 432/16 octobre $1040^{66}$, le colophon est écrit dans une graphie coufique maghrébine, tandis que le texte coranique lui-même, vocalisé suivant les conventions maghrébines, l'est dans un " early type of "classical" Maghribī calligraphy ${ }^{67}$ ".

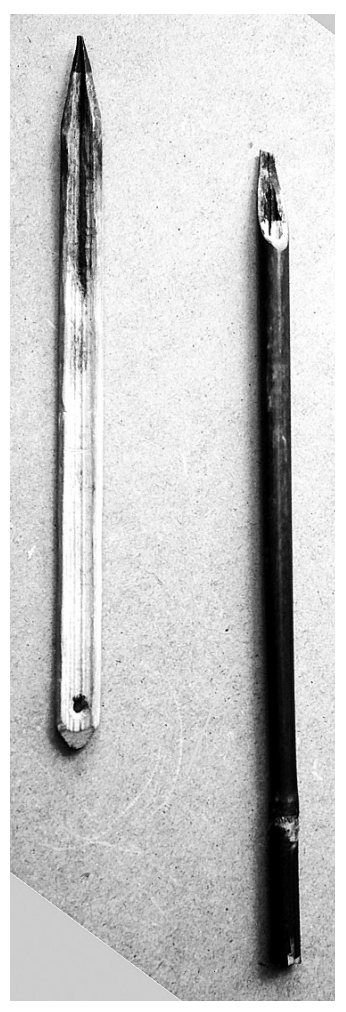

\section{Les corans en " écriture maghrébine " ou Maghribī}

Si la notion de " coufique occidental " ou " maghrébin " est assez récente ${ }^{68}$, celle d' "écriture occidentale " ou " maghrébine " (alqalam al-maghribi) est très ancienne : elle remonterait au IX $\mathrm{IX}^{\mathrm{e}}$ siècle ${ }^{69}$. Elle désigne communément une famille d'écritures rondes qui se caractérisent par un certain nombre de formes communes, en particulier des courbes très accentuées : plusieurs lettres sont très concaves, voire semi-circulaires (fig. $6,7,8)^{70}$. Dans la lignée de ce qui a été mis en évidence pour le " coufique occidental/ maghrébin ", l'épaisseur des traits est assez uniforme, ce qui est communément expliqué par l'instrument utilisé pour l'écriture. Contrairement aux calames orientaux, de fins roseaux dont l'extrémité est taillée en carré ou plus généralement en biseau, les calames traditionnels de l'Occident musulman sont de larges roseaux coupés en deux dans le sens de la longueur, de manière à obtenir deux demi-roseaux dont l'extrémité est ensuite taillée non pas en biseau, mais en pointe ${ }^{71}$ (fig. 5).

Les questions de l'origine et de l'histoire de l' « écriture maghrébine » ont fait couler beaucoup d'encre : le nom même de Maghribī et le prestige pionnier de Kairouan ont induit l'idée que le Maghribī a vu le jour et s'est diffusé à partir de cette ville ${ }^{72}$. Cependant, quelques références médiévales, en particulier un passage de la Muqaddima 
du grand historien Ibn Khaldūn (1332-1406), ont suggéré à certains chercheurs la possibilité d'une origine non pas à Kairouan, mais en Andalousie ${ }^{73}$, ce qui a été confirmé par l'analyse des plus anciens manuscrits connus en Maghribī, datant de la seconde moitié du Xe siècle. Contrairement à ce que son nom semble indiquer, le Maghribī est donc une écriture andalouse qui s'est diffusée au Maghreb ${ }^{74}$. De plus, elle apparaît d'abord comme une écriture livresque, avant de devenir une calligraphie coranique ${ }^{75}$. Le premier coran en Maghribī qui nous soit parvenu est un fragment oblong $(14,8 \times 20,2 \mathrm{~cm})$ daté de Rajab 398/mars-avril $1008^{76}$.

La question des sources du Maghribī reste cependant ouverte. Plusieurs chercheurs, comme Octave Houdas, Jean David-Weill ou Adolf Grohmann, ont observé des similarités entre certaines lettres maghribī et certaines graphies plus orientales, comme celles des papyri, surtout les papyri littéraires égyptiens des VIII ${ }^{\mathrm{e}}$-IX $\mathrm{X}^{\mathrm{e}}$ siècles, qui ont donc été qualifiées d' « écriture maghrébine ancienne " ou de "Protomagrab $\overline{1}^{77}$ ». François Déroche a confirmé ces observations en soulignant que les papyri des premiers siècles de l'Islam semblent avoir été écrits à l'aide d'un calame pointu, et que les écritures livresques orientales, abbassides, sont attestées dans l'ensemble de l'Occident musulman, du Maghreb à l'Andalousie, du milieu du IX ${ }^{\mathrm{e}}$ au milieu du XI ${ }^{\mathrm{e}}$ siècle. Il a cependant apporté une nuance : " s'il n’y a pas lieu de contester leur parenté [écritures livresques abbassides et Maghribī], [...] le rapport de filiation [...] paraît moins assuré. [...] l'écriture livresque abbasside aurait représenté un courant parallèle et concurrent du Maghribī, non pas un précurseur ${ }^{78}$ ". Autrement-dit, au lieu d'une simple succession : écritures des papyri - écritures livresques abbassides - Maghribī, l'auteur a imaginé un scénario légèrement différent selon lequel l'écriture des papyri serait à l'origine de deux développements parallèles : écritures livresques abbassides d'un côté et Maghribī de l'autre, selon lequel, de plus, le premier aurait fini par disparaître au profit du second ${ }^{79}$. Cependant, cette vision des choses a été critiquée pour plusieurs raisons, en particulier parce qu'elle ne s'appuie pas sur des jalons localisés et datés avec précision ${ }^{80}$.

Arianna D'Ottone a, quant à elle, tourné son regard vers un autre type de matériel : les manuscrits bilingues, et plus particulièrement un fragment arabe-latin du Nouveau Testament attribuable à l'Espagne au tournant des $\mathrm{IX}^{\mathrm{e}}-\mathrm{X}^{\mathrm{e}}$ siècles. En observant plusieurs convergences entre les deux alphabets, sans doute ouvre de la même main et du même calame, elle s'est interrogée sur le rôle des copistes chrétiens formés dans la tradition visigotique et sur le "mimétisme graphique " dans la naissance du Maghribīi ${ }^{81}$. Umberto Bongianino, qui a consacré sa thèse de doctorat aux plus anciens manuscrits en Maghribī connus ( $\mathrm{X}^{\mathrm{e}}$ $\mathrm{XII}^{\mathrm{e}}$ siècles $)^{82}$, a soutenu cette hypothèse en définissant plus précisément le Maghribī comme une écriture "professionnelle " (an improved form of cursiveness) et en retraçant précisément son itinéraire des livres vers les corans au XI ${ }^{\mathrm{e}}$ siècle, puis de l'Andalousie vers le Maghreb au XII ${ }^{\mathrm{e}}$ siècle. Selon lui, le plus ancien manuscrit connu qui fut copié en Maghribī au Maghreb proprement dit est un exemplaire du Muwațta' de Mālik réalisé par un prince sévillan pour la bibliothèque d'un souverain almoravide, 'Alī b. Yūsuf b. Tāshfīn, à Marrakech en 502/1109. Quant au premier coran, il a été copié à Ceuta en 587/119183.

En reconstituant l'évolution précise du Maghribī, Bongianino a apporté une autre nuance. En effet, il a démontré que les écritures andalouses se sont d'abord diffusées dans le Maghreb occidental et central, dans des villes telles que Marrakech, Fès, Ceuta, Tlemcen, Sijilmasa, ou Bijāya, tandis que l'Ifrīqiyya a continué à utiliser des graphies plus proches des écritures livresques abbassides jusqu'à la fin du XIII ${ }^{\mathrm{e}}$ siècle, avec des traces au moins jusqu'au XIV e siècle. Selon Bongianino, mis à part quelques exceptions non pas " proto-" , mais « semi- " ou "pseudo-maghrébines », " clumsily imitating the ductus of Maghribī [...] round, harmonious traits mastered by then by most Andalusī scribes ${ }^{84}$ ", qui témoignent des contacts continus entre l'Andalousie, le Maghreb occidental et central et l'Ifrīqiyya et qui sont d'ailleurs souvent difficiles à attribuer à un lieu précis, les premières traces d'écriture andalouse 
ou maghrébine en Ifrīqiyya apparaissent dans la correspondance entre les gouverneurs et les notables almohades de Tunis et le gouvernement pisan au début du XIII ${ }^{\mathrm{e}}$ siècle, tandis que le premier livre, et coran, en Maghribīifrīqiyyen daté connu est un manuscrit en quatre volumes, sur parchemin, réalisé à Tunis en 706/1306 85 (fig. 7). Cette image doit cependant être nuancée car la production de manuscrits en Ifrīqiyya a été sévèrement freinée par les invasions hilaliennes et le sac de Kairouan en 1057, si bien qu'aucun codex écrit dans cette région entre cette date et la fin du XIII ${ }^{\mathrm{e}}$ siècle ne semble avoir pu être conservé ${ }^{86}$.

Ainsi, il apparaît que les recherches sur les origines rejoignent la volonté d'affiner la classification du Maghribī, notamment la distinction entre écritures andalouses et proprement maghrébines et entre les graphies du Maghreb elles-mêmes. Cette volonté est ancienne et partagée par de nombreux chercheurs. Cependant, la nuance " andalou " / " maghrébin " se limite généralement à la taille : l'andalou est petit, tandis que le maghrébin est grand $^{87}$. Quant aux classifications des écritures du Maghreb elles-mêmes, elles sont le plus souvent purement spéculatives, uniquement basées sur un certain sentiment des identités nationales et régionales, en lien avec l'histoire des grands centres intellectuels et culturels - écriture de Fès $(f \bar{a} s \bar{\imath})$, des bédouins (badawī), du sud du Maroc (sūsī), du Sahara (șaḥrāwì)), de l'Ifrīqiyya (ifrīqū), de Kairouan (qayrawānī), de Tunis (tūnisī̄), de Tumbuktu ou du Soudan

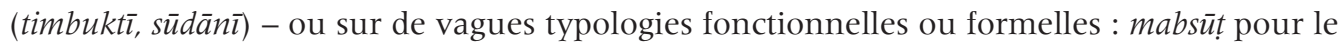
Coran, mujawhar pour les manuscrits non coraniques et les documents, musnad ou zimāmī, pour les écritures plus cursives, etc ${ }^{88}$.

En vérité, seuls quelques chercheurs ont procédé à des analyses paléographiques systématiques et approfondies dans cette perspective. Parallèlement à Bongianino et à son travail sur les manuscrits andalous, du Maghreb occidental et central, et ifrīqiyyens, nous devons mentionner Jaouhari qui a aussi tenté de définir quelques «types " de Maghribī sur des bases paléographiques. Ainsi, dans un premier article ${ }^{89}$, Jaouhari a identifié deux grands " groupes" ( 1 et 2 ) formés l'un de sept, l'autre de trois " types " Dans un second article ${ }^{90}$, il a tenté d'identifier certains «spécimens » du groupe 2 avec ce qu'une source médiévale appelle "l'écriture de l'Andalousie orientale ». En ciblant les spécimens autographes d'ulémas de cette région (Murcie, Valence) aux $\mathrm{XI}^{\mathrm{e}}$-XIII ${ }^{\mathrm{e}}$ siècles, il a mis en évidence plusieurs convergences. D'une manière générale, il s'agit, explique-t-il, d'un "style hybride combinant des formes issues de la tradition orientale et d'autres émanant de la tradition de l'Occident musulman ", mais on est encore loin "des courbes prononcées" du Maghribīi ${ }^{91}$. Cependant, il reste à savoir si ces exemples " extrêmement rares " sont à interpréter comme les témoins d'un style régional, ou s'ils doivent être soumis à une autre grille de lecture, par exemple dans la lignée des situations de continuité ou de revival mentionnées ci-dessus. En effet, les cinq cas étudiés sont des ouvrages de Ḥadīth, et trois d'entre eux des certificats de transmission, ce qui permet de se poser encore une fois la question de la valeur archétypale de ces graphies, en particulier dans le contexte de la transmission des sciences religieuses. Reste à savoir aussi si ces traits ne se retrouvent pas ailleurs qu'en Andalousie orientale, et dans les corans.

\section{Autres caractéristiques formelles des corans de l'Occident musulman médiéval : supports, formats, décors}

Parallèlement aux écritures et en particulier au Maghribī, plusieurs autres caractéristiques formelles distinguent les corans de l'Occident musulman des autres manuscrits produits dans la même région et en Orient. La première est le support. Le papier est introduit dans l'Orient

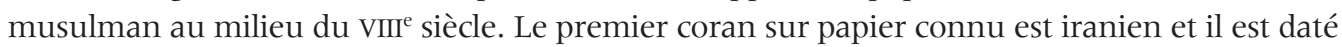


de $361 / 972^{92}$. C'est à partir de cette même époque, la seconde moitié du $\mathrm{X}^{\mathrm{e}}$ siècle, que la production de papier est aussi attestée dans l'Occident islamique ${ }^{93}$. Cependant, à quelques exceptions près ${ }^{94}$, le Coran continue à y être copié sur parchemin pendant encore au moins deux siècles.

Cette continuité peut s'expliquer de plusieurs manières : le caractère conservateur des milieux religieux où l'on suppose que les manuscrits coraniques étaient produits et utilisés ; la révérence envers les corans des premiers siècles, conservés comme des reliques dans des lieux vénérés, et la volonté de les imiter; ou encore le désir d'honorer le texte sacré en mettant en œuvre les matériaux les plus coûteux, ce qui, d'ailleurs, vaut aussi pour quelques autres textes malikites de première importance comme les œuvres de Mālik, Saḥnūn, Ibn Abī Zayd al-Qayrawānī, etc. ${ }^{95}$. Comme le dit Bongianino, "parchment maintained [...] an aura of quality and prestige ${ }^{96}$ ", et il semble que ce soit un mécénat royal actif, celui des Almohades, qui ait encouragé l'emploi du papier pour les manuscrits coraniques à partir de la première moitié du XIII ${ }^{\mathrm{e}}$ siècle, comme le suggère une série de corans en plusieurs volumes, sur papier, de grand format, qui sont associés à des souverains almohades ${ }^{97}$ (fig. 6). Leur chute et l'avènement des Mérinides, des Nasrides et des Hafsides marquent le retour des corans sur parchemin ${ }^{98}$ (fig. 7), ce qui appuie l'hypothèse de la valeur symbolique forte de cette association. En effet, selon Bongianino, l'association Coran-parchemin aurait été favorisée par les juristes malikites ; c'est par réaction à ces derniers, accusés d'avoir négligé les sources (le Coran et les traditions prophétiques, Hadìth) au profit des ouvrages de droit malikite, que le papier eut la préférence des Almohades ${ }^{99}$. En définitive, on continue à produire des corans sur parchemin jusqu'au XVI ${ }^{\mathrm{e}}$ siècle ${ }^{100}$, même si le papier, notamment le papier filigrané italien s'impose petit à petit à partir du XIV siècle ${ }^{101}$ (fig. 8).

Une autre caractéristique des corans de l'Occident musulman est leur format. Comme nous l'avons déjà indiqué, les premiers corans occidentaux sont difficiles à distinguer de leurs pendants orientaux, aussi bien du point de vue des graphies et des supports que des formats. En règle générale, les corans en coufique et les premiers corans en NS sont de format oblong, tandis que d'autres corans en NS sont de format vertical (par exemple le Coran de la Nourrice).

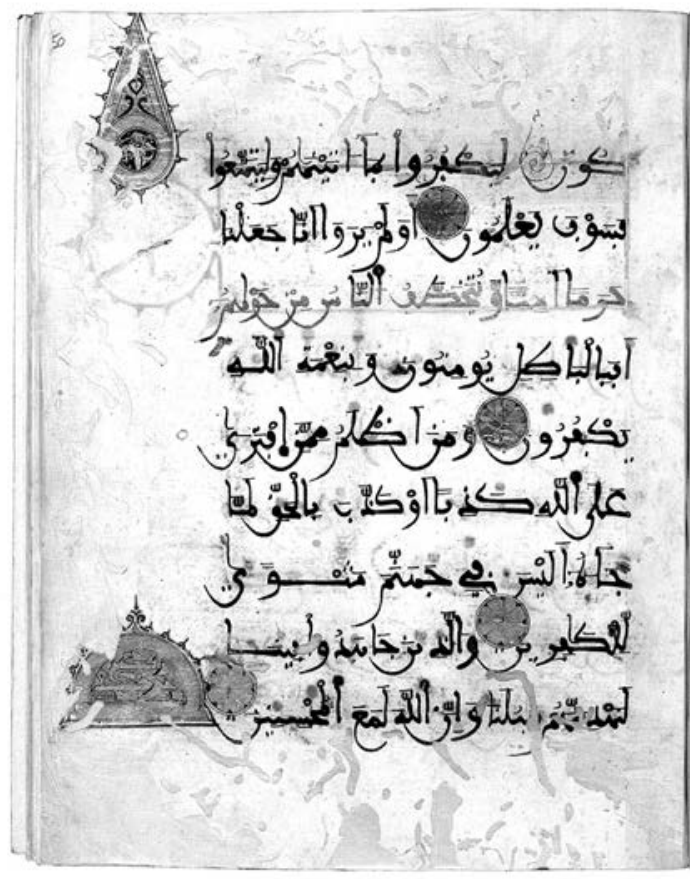

6. Page d'un Coran en 10 volumes, calligraphié par le calife almohade al-Murtadāā, Marrakech (?), $654 / 1256$, parchemin, Londres, British Library, Ms. Or. 13192, fol. $50 r^{\circ}$.

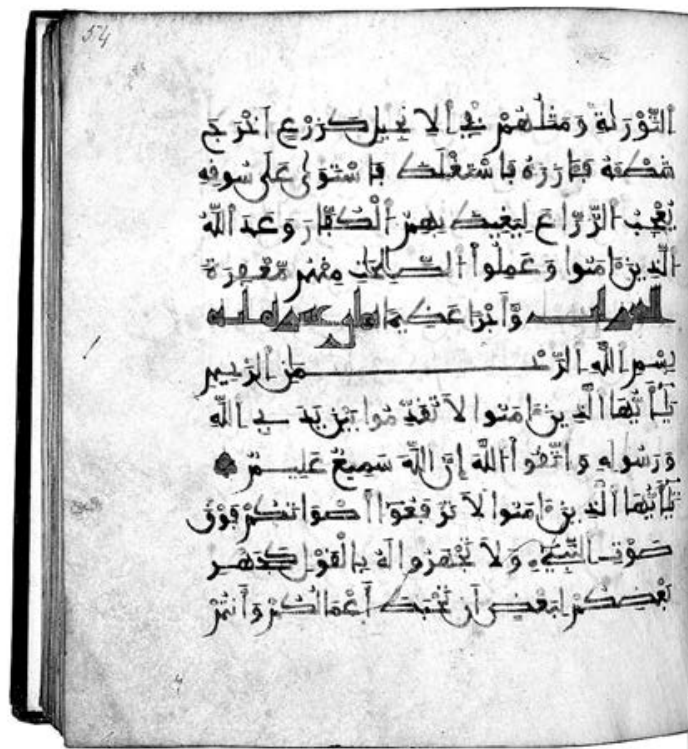

7. Page du quatrième volume d'un Coran en quatre volumes, copié par Muḥammad b. Hasan b. Ah mad al-AzdT, Tunis, 706/1306, parchemin, Londres, British Library, Ms. Add. 11638, fol. $54 r^{\circ}$. 
8. Page d'un Coran en cinq volumes, encre argentée et dorée sur papier teinté pourpre, offert par le sultan hafside Abū Fāris 'Abd al-'Azīz (r. 796-837/ 1394-1434) à la mosquée de la Qaşba à Tunis vers 807/1405 Paris, BnF, Arabe 389 à 392, fol. 19 .

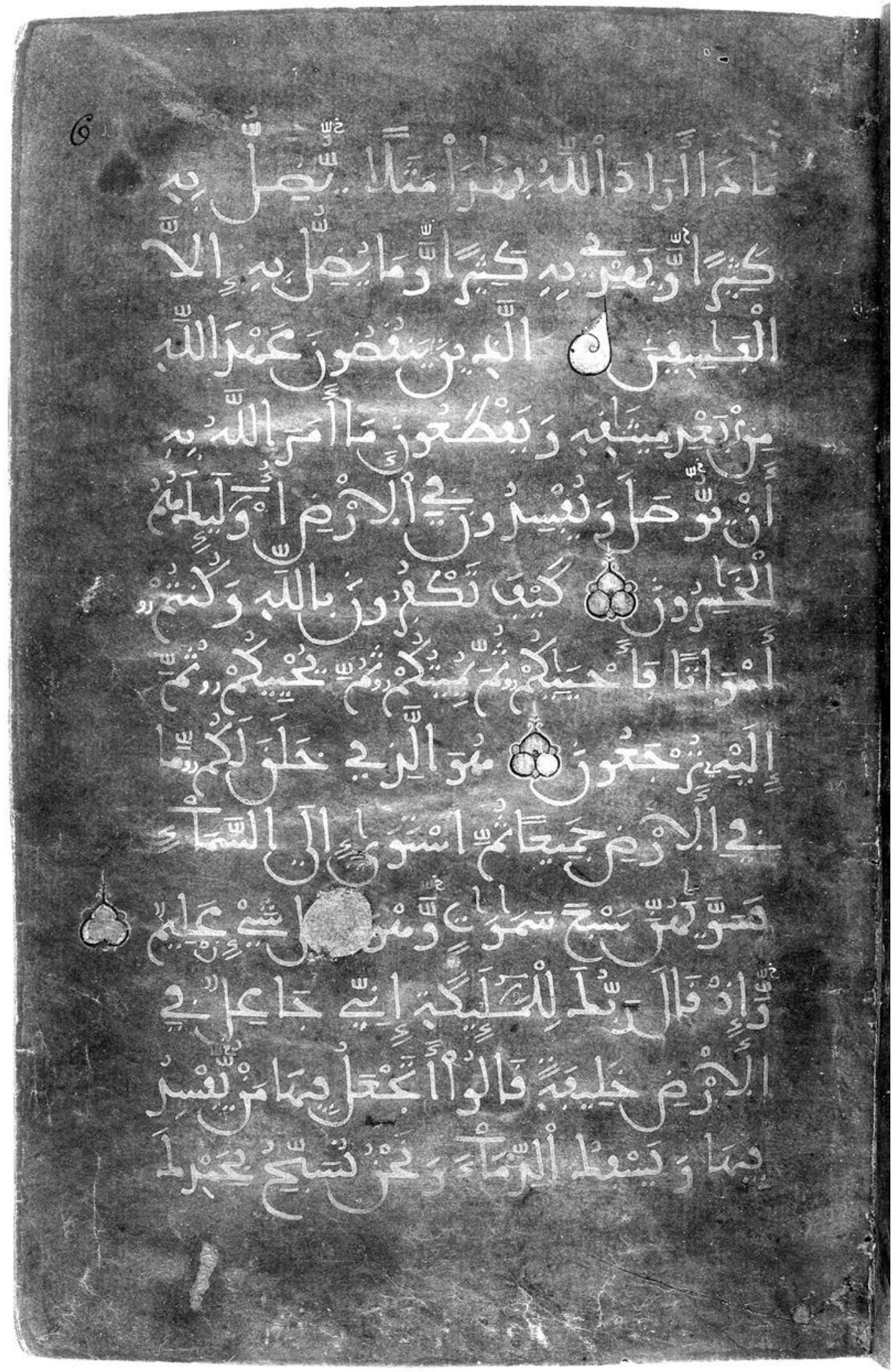


En revanche, les corans en Maghribī sont souvent de format carré (fig. 9). Le premier coran en Maghribī carré connu a été réalisé pour un vizir cordouan en 470/1078 $(7,9 \times 7,9 \mathrm{~cm})^{102}$. Il est suivi par de nombreux autres manuscrits, d'abord presque exclusivement andalous, puis maghrébins, en particulier du XII ${ }^{\mathrm{e}}$-XIII ${ }^{\mathrm{e}}$ siècles ${ }^{103}$. Comme le parchemin et le format oblong qui sont presque exclusivement réservés aux corans, à l'exception de quelques autres textes religieux, le choix du format carré s'explique très vraisemblablement par la volonté de distinguer Le(s) Livre(s) sacré(s) de tous les autres manuscrits de format à la française ${ }^{104}$, jusqu'à l'adoption définitive de ce dernier au XIV ${ }^{e}$ siècle.

De plus, la très grande majorité des corans de l'Occident musulman sont de petites dimensions, ne dépassant pas $25 \mathrm{~cm}$, mais dont le côté le plus long mesure généralement environ 16 à $18 \mathrm{~cm}$. Selon Bongianino, la Reconquista pourrait expliquer cet état de fait : seuls les manuscrits transportables seraient parvenus jusqu'à nous, tandis que les corans de grandes dimensions, difficiles à transporter et à cacher, auraient, pour l'essentiel, disparus, du moins en Espagne ${ }^{105}$. En effet, les sources textuelles nous informent de l'existence de corans monumentaux, comme par exemple un coran attribué au calife 'Uthmān, en Andalousie, dont les rares exemples conservés ne se trouvent pas en Espagne, mais au Maghreb (ou dispersés). C'est le cas de plusieurs corans de Kairouan (par exemple le Coran bleu ou les corans des Zirides, en particulier le Coran de la Nourrice), mais aussi des corans royaux almohades : si certains ont été réalisés en Espagne (Malaga, Séville), tous les exemplaires conservés sont passés par le Maroc où ils ont été constitués hạbūs au profit de mosquées ou de mausolées.

Les corans habūs ne sont pas seulement grands, mais aussi épais, puisqu'ils sont généralement formés de plusieurs volumes $(2,3,4,5,7,8,10,12,14,20,30 \text { ou } 60 \text { volumes })^{106}$. Outre les exemples mentionnés ci-dessus, nous pouvons aussi citer un célèbre coran en cinq volumes en papier pourpre écrit à l'encre argentée qui a été offert par le souverain hafside Abū Fāris 'Abd al- 'Azīz (r. 796-837/1394-1434) à la mosquée de la Qaṣba à Tunis vers 807/1405 (fig. 8$)^{107}$; ou encore la «bibliothèque de corans " (khizānat al-mașāhif) fondée par le souverain mérinide Abū 'Inān (r. 749-59/1348-1359) au sud de la Grande Mosquée de Fès ${ }^{108}$.

Ces différents aspects soulignent la volonté de distinguer matériellement et visuellement les corans des autres manuscrits, aussi bien en Orient qu'en Occident musulman, sinon de manière toujours plus accentuée, en tout cas plus durable en Occident musulman, comme en témoignent la longévité, voire le revival du parchemin et le format carré. Pour Déroche, les manuscrits coraniques ont essentiellement " une fonction d'apparat ». En effet, ils assurent la présence physique, sensible et visible, aussi bien de la parole divine révélée que de l'acte de piété du donateur dans l'espace, au centre de la cité, "sous le regard de la communauté109 "; et l'œuvre pieuse est d'autant plus remarquable qu'elle est luxueuse (parchemin, grandes dimensions, nombreux volumes). Dans l'Occident musulman, les manuscrits coraniques apparaissent en outre comme un terrain où s'expriment les positions religieuses. Ainsi, le coran réalisé à Palerme en 982-983 affirme la doctrine orthodoxe de la nature incréée du Coran. Celui constitué habūs par al-Mu izz b. Bādis exprime la haine (bughḍ) du prince à l'égard de la dynastie fatimide. D’une manière plus générale, le caractère plus normé de la production coranique occidentale, ainsi que les parallèles formels établis entre celle-ci et certains autres textes religieux, d'abord malikites, puis almohades, est donc sans doute à imputer à la puissance de la doctrine malikite, puis à la véhémence de la propagande almohade.

À côté des matériaux et des formats, d'autres éléments formels distinguent les corans, et les honorent : les enluminures et les reliures. Les recherches sur les enluminures coraniques de l'Occident musulman en sont encore à leurs débuts. Déroche a étudié les manuscrits les plus anciens ; Marianne Barrucand et ses disciples, en particulier Élisabeth Dandel, les corans almoravides, almohades, mérinides et nasrides ; Alamut von Gladiss les corans saadiens ${ }^{110}$. D'autres informations apparaissent dans les catalogues d'exposition et de vente. D'une manière 
9. Deux pages d'un Coran,

copié et enluminé par 'Abdallah b. Muh ammad b. 'Ali

(Ibn Ghatțūs père), pour Yāsin b. Yāsin, Valence, 558/1163, parchemin, $17,5 \times 16 \mathrm{~cm}$, 27 lignes par page, Tunis, Bibliothèque nationale de Tunisie, $n^{\circ} 13727 / 18791$, fol. $1 v^{\circ}-2$.

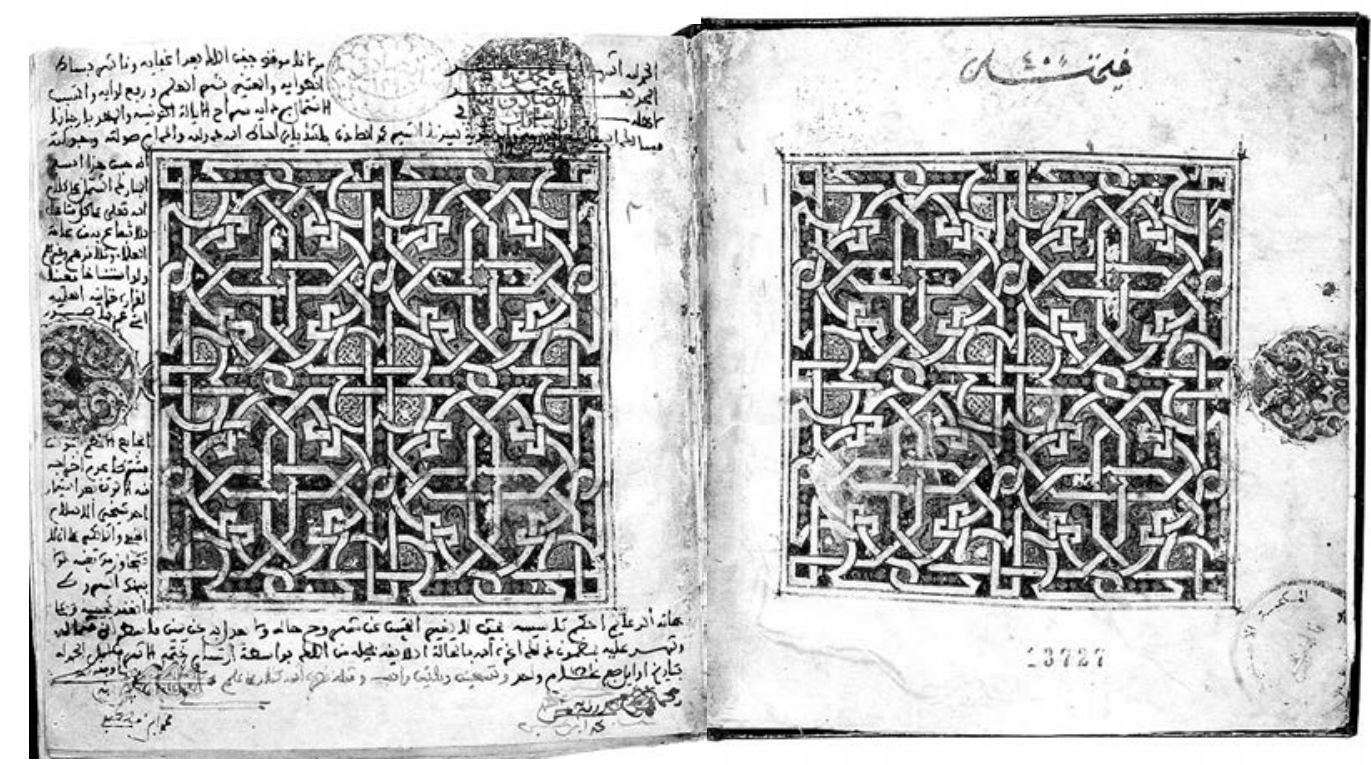

générale, ces enluminures se composent d'un double-frontispice (fig. 9), puis de décors qui marquent les divisions du texte coranique. Certaines apparaissent dans la surface écrite (sourates, versets), d'autres dans la marge (soixantièmes [hizb], trentièmes [juz'], groupes de cinq et dix versets, prosternations rituelles [sajda]). Le manuscrit contient aussi parfois un finispice. La méthodologie proposée par la plupart des chercheurs consiste à décrire d'abord la structure, puis le remplissage.

Déroche a attiré l'attention sur l'importance de l'élément carré dès les premiers siècles. Ainsi, dans les corans de format oblong, le frontispice apparaît souvent comme deux carrés placés côte à côte. Le frontispice peut porter des inscriptions, par exemple des versets du Coran qui font office de titre (comme les versets 56:76-80), ou une louange à Dieu, mais il est généralement anépigraphe. Il est composé d'un cadre simple ou double (ligne, bande, tresse, bandeau orné d'un rinceau...), et d'un champ décoré d'un treillage de figures géométriques (cercles, carrés posés sur la pointe, étoiles...). À partir du XII siècle apparaissent des compositions centrées autour d'un grand carré, lui-même inscrit dans un grand cercle et/ou dans un grand médaillon polylobé ou d'une grande étoile. Treillages et figures géométriques sont dessinés à l'aide d'un entrelacs de rubans généralement formés de deux filets dorés de part et d'autre d'un espace réservé ou blanc, parfois rythmé de motifs simples (points, hachures...). Les compartiments géométriques sont, quant à eux, remplis de motifs géométriques abstraits (crosses, croix, quadrillage...) et/ou végétaux stylisés (demi-palmettes, palmettes, quatrefeuilles, rinceaux...). Au même moment, les motifs géométriques se raréfient et les motifs végétaux s'affinent considérablement. Par ailleurs, dans la marge de gouttière apparaît une vignette médiane. Dans les premiers corans, celle-ci prend la forme d'une grande palmette ou d'un grand motif pseudo-végétal composite. Ensuite, elle est lancéolée et ornée de rinceaux ou d'arabesques et parfois accompagnée de deux vignettes latérales de forme et de décor analogues. En règle générale, les motifs sont dorés et se détachent sur le support en réserve et/ou sur un fond coloré (rouge, bleu, plus tard vert, etc.).

Ces caractéristiques générales perdurent durant plusieurs siècles en donnant lieu à de nombreuses variations. Par exemple, dans les corans de format vertical, un bandeau rectangulaire est ajouté en haut et en bas du carré central. Celui-ci peut être orné non pas d'une composition géométrique, mais d'un décor pseudo-végétal tapissant. Les motifs 
végétaux peuvent être peints en blanc. Certains décors semblent circonscrits à des lieux et à des périodes bien précis. C'est le cas d'une série de corans signés par ou attribués à l'atelier d'une famille de calligraphes et enlumineurs valenciens de la deuxième moitié du XII ${ }^{\mathrm{e}}$ siècle : les Ibn Ghațtūụ, ainsi qu'à leurs disciples ${ }^{111}$ (fig. 9). À cette même période, d'une manière plus générale, deux innovations sont attribuées aux Almohades. La première est l'emploi d'une forme d'écriture très arrondie, appelée "Thuluth maghrébin ", dans le paratexte des corans (frontispices, titres des sourates, inscriptions marginales, colophons) ${ }^{112}$. La seconde est un motif de rinceau spiralé traité en trait noir sur fond d'or qui évoque la gravure sur métal, qui n'est attesté qu'aux XII ${ }^{\mathrm{e}}$-XIII ${ }^{\mathrm{e}}$ siècles ${ }^{113}$.

Les recherches sur les enluminures des corans occidentaux ont donc permis d'identifier un certain nombre de constantes et de variantes. Elles restent cependant encore éclatées. Un inventaire systématique des décors, des compositions et des motifs, mais aussi des pigments ${ }^{114}$, au moyen d'une base de données, permettrait d'affiner les typologies, les attributions et les analyses des phénomènes de production et de circulation, notamment entre les corans et les copies d'autres textes. En effet, dans le domaine de l'enluminure aussi, on assiste à un transfert des manuscrits coraniques vers les ouvrages de référence du malikisme, puis vers ceux de la doctrine almohade. Il s'agit donc d'un phénomène cohérent qui peut être expliqué par la grande estime, voire la vénération de ces textes dans les milieux religieux de l'Occident musulman ${ }^{115}$, mais qui n'est pas encore documenté avec toute la précision nécessaire. Par ailleurs, il serait fort intéressant également de comparer les enluminures de l'Occident musulman avec les décors des objets et de l'architecture, aussi bien dans cette région qu'en Orient.

Enfin, quelques mots sur les reliures. Le fonds de Kairouan comprend plus de cent cinquante reliures détachées, mais qui devaient, pour la plupart, être associées à des corans datables du IX ${ }^{\mathrm{e}}$ au XIII ${ }^{\mathrm{e}}$ siècles. Ces reliures ont été étudiées par Georges Marçais et Louis Poinssot ${ }^{116}$. Les plus anciennes, de format oblong, sont des « reliure-boîtes " ou " coffres ». Elles sont formées de planchettes de bois recouvertes de cuir à l'extérieur et de parchemin à l'intérieur. Ces planchettes se ferment au moyen d'une lanière de cuir ou de soie attachée au plat inférieur, qui vient s'accrocher à un piton métallique implanté dans l'épaisseur ou fixé sur la face externe du plat supérieur. Les couvrures peuvent être décorées de deux manières : soit en relief, au moyen de ficelles ou de pastilles de cuir collées entre les planchettes et la couvrure en cuir ; soit en creux, à l'aide de petit fers de formes, tailles et décors différents. Les reliures plus tardives, de format vertical, sont des "reliures à rabat ", c'est-à-dire composées de deux plats, un rabat rectangulaire et un recouvrement pentagonal en carton, qui sont recouverts d'une couvrure en cuir, elle-même décorée au moyen de petits fers, et parfois dorée. Enfin, la couvrure est accompagnée d'une doublure en cuir ou en étoffe. Ce dernier type connaît une très grande continuité, comme en témoignent de nombreux autres spécimens conservés ${ }^{117}$. L'un des grands enjeux des recherches sur les reliures consiste donc à les dater de manière à pouvoir en retracer l'histoire, et les chercheurs actuels, qui viennent souvent du domaine de la restauration, ont pris conscience de l'importance de l'analyse technique des coutures, des cuirs et des fers pour sortir des généralités et parvenir à des résultats probants ${ }^{118}$.

Enfin, il faut aussi signaler que les seuls traités techniques écrits sur l'art de la reliure dans le monde islamique pré-moderne sont maghrébins, dans l'ordre chronologique : Le soutien des scribes et l'équipement de ceux qui sont doués d'intelligence ('Umdat al-kuttāb wa 'uddat dhawī $a l$-albāb), attribué à l'Ifrīqiyya ziride ; Le livre du succès dans l'art de la reliure (Kitāb al-taysīr fì șinā 'at al-tasfîr), d'un auteur almohade, Abū Bakr al-Ishbīlī ; L'art de la reliure et de la dorure (Șinā at tasfír al-kutub wa hall al-dhahab), rédigé par un auteur saadien, Abū al- 'Abbās Aḥmed b. Muhammad al-Sufyān̄̄, en $1619^{119}$. Ces textes, et cet intérêt particulier pour le métier de la reliure au Maghreb, gagneraient sans doute à être relus à la lumière des connaissances nouvelles dans ce domaine. 


\section{Les fonctions des manuscrits coraniques dans l'Occident musulman médiéval}

Les manuscrits coraniques avaient-ils une fonction liturgique ? Si les prières quotidiennes, ou les prières collectives du vendredi et des grandes fêtes religieuses, qui sont accompagnées d'un prêche, n'incluent qu'une lecture à partir d'un exemplaire du Coran, cela n'a pas empêché le développement d'un culte et d'un rituel autour de quelques codex emblématiques. C'est le cas du Coran dit de 'Uthmān, mentionné ci-dessus ${ }^{120}$. Il s'agit plus exactement d'un fragment de coran, et selon les sources, du coran écrit par le calife lui-même et maculé de son sang au moment de son assassinat à Médine, ou de l'une des quatre copies officielles établies sous son autorité à Médine, puis envoyées à La Mecque, Basra, Kufa et Damas. Mais, selon les recherches les plus récentes de Déroche, il s'agit plus vraisemblablement d'un exemplaire du VIII ${ }^{\mathrm{e}}$ ou du IX $\mathrm{X}^{\mathrm{e}}$ siècle qui a été identifié comme une relique umayyade et placé dans la Grande Mosquée de Cordoue où il a été signalé par plusieurs auteurs au milieu du XII siècle.

Chaque vendredi, deux serviteurs le tiraient de la réserve (mahzan) où on le conservait, et, précédés d'un troisième serviteur tenant un cierge, le portaient au kursī (pupitre) en bois d'aloès décoré de clous d'or, qui lui était réservé à l'endroit où l'imām faisait la prière. Dès que la lecture du Livre saint était terminée on le rapportait à sa place habituelle ${ }^{121}$.

Le premier calife almohade 'Abd al-Mu'min (524-558/1130-1163) est entré en possession de ce coran, considéré comme " l'éclat " et " la splendeur " de Cordoue et de l'Andalousie ${ }^{122}$, et l'a déposé dans la Grande Mosquée de la capitale, Marrakech, en 552/1157-1158, puis dans celle de la ville sacrée, centre du mouvement almohade, lieu de sépulture des califes et destination de pèlerinage : Tinmal. À Marrakech et Tinmal, le coran a reçu tous les honneurs de la part de 'Abd al-Mu'min et de ses successeurs, en particulier une reliure orfévrée et un pupitre intégré dans un cabinet automatique. Le manuscrit semble avoir été sorti régulièrement, notamment pour accompagner les expéditions militaires, et c'est d'ailleurs lors d'une bataille qu'il a été saisi par les Abdalwadides de Tlemcen en 645/1247, avant d'être repris par les Mérinides un siècle plus tard, et enfin définitivement perdu en mer peu de temps après.

$\mathrm{Au}$ moins deux autres corans-reliques ont fait partie des collections almohades. Le premier est un coran attribué au, ou réalisé pour le grand conquérant du VII ${ }^{e}$ siècle, et fondateur de Kairouan, 'Uqba b. Nāfi' (m. 683) ${ }^{123}$. Le second et le plus important est un muṣhaf copié par le fondateur de la dynastie almohade, le Mahdī Ibn Tūmart, qui a été conservé dans la même pièce que le coran de 'Uthmān à Tinmal et, comme lui, a été sorti lors des expéditions militaires ${ }^{124}$. Quelques corans sont connus pour avoir fait l'objet de lectures, voire de cultes et de rituels publics en Orient, par exemple à La Mecque, à Médine ou à Damas, dès l'époque umayyade ${ }^{125}$. Le coran de 'Uthmān de Cordoue apparaît donc être une relique non seulement d'un objet, mais aussi d'une pratique umayyade, que les souverains postérieurs, en particulier almohades se sont appropriée en en accentuant l'identité maghrébine (le coran de 'Uqba) et plus particulièrement almohade (le muṣhaf d'Ibn Tūmart). Les corans du calife et du Mahdī faisaient l'objet de cérémonies publiques : ils étaient lus à haute voix, exposés, éventuellement touchés, portés en procession, mis en scène dans des lieux et/ou pour des occasions qui servaient la propagande almohade. Mais nous pouvons dire que cette fonction de prestige et cette dimension "performative " sont aussi présentes, bien qu'à des degrés bien moindres, dans tout acte de donation d'un exemplaire coranique à une mosquée ou une autre institution religieuse. Comme indiqué précédemment, cette pratique était d'ailleurs très fréquente dans les cercles royaux - dans une finalité de légitimation parfois évidente, surtout en contexte hostile, comme dans le cas des Zirides - mais elle était aussi courante dans les milieux savants ou même populaires ${ }^{126}$. 
Nous ne sommes pas très bien informés sur les lectures publiques du Coran au sein des mosquées et autres institutions religieuses. Si des lectures publiques, organisées par l'État, sont évoquées dès l'époque umayyade, nous ne savons que très peu de choses sur leur contenu, leur temporalité, leur rythme, leurs acteurs ou leurs publics. Ainsi, selon son disciple Ibn Zabāla (m. au début du IX siècle), l'imam de l'école malikite, Mālik b. Anas (m. 796), aurait évoqué un grand coran envoyé par le gouverneur umayyade al-Ḥajjāj (m. 714) à la mosquée de Muhammad à Médine. Ce coran était conservé dans un coffre placé à droite de la colonne qui marquait l'emplacement du tombeau du prophète et, le jeudi et le vendredi, au moment de la prière du matin $(s ̦ b h)$, il était sorti pour être lu par les fidèles. Mālik lui-même était opposé à cette pratique ${ }^{127}$. Des données plus précises sont disponibles à partir de la période almohade. Ainsi, le deuxième calife almohade Abū Ya 'qūb Yūsuf (r. 1163-1184) a recruté des lecteurs pour la mosquée Qarawiyȳnn, pour y lire le Coran après les prières du matin et du coucher du soleil (maghrib). Le hafside Abū 'Umar 'Uthmān (r. 1435-1488) a nommé quatre lecteurs dans la mosquée de la Qaṣba à Tunis en 869/1464, avec pour mission de lire après les prières du matin, de midi (zuhr) et de l'après-midi ( 'așr). Une fatwa mentionne aussi des lecteurs de hizb (hazzābūn) dans la Grande Mosquée de Fès al-Jadīd au XVe siècle ${ }^{128}$. Autant d'éléments qui suggèrent que les corans en plusieurs volumes étaient probablement destinés ou, en tout cas, particulièrement adaptés à ce type de lecture, chaque lecteur lisant un volume différent, simultanément, dans le but de bénir à la fois l'espace, le temps, notamment en plaçant la journée, dès la première prière, sous la protection du Livre sacré, et les individus présents qui se trouvaient ainsi enveloppés, voire pénétrés par la Parole divine.

Les corans déposés dans les institutions publiques pouvaient aussi être utilisés comme support d'enseignement. Ainsi, une note écrite sur un juz' de coran en Maghribī mentionne des séances de lecture (majālis) tenues à Valence en 630/1232. Durant ces séances, le copiste et le propriétaire du juz', qui connaît le coran par cœur (hâfiz), Aḥmad b. Muhammad b. Ḥasan al-Ṣadafī al-Shātịīi (m. 674/1276) a étudié la lecture coranique de Warsh et a été autorisé à la transmettre par un certain Ibrāhīm b. Muḥammad b. Wāthiq al-Ishbīlīin . Aussi pouvons-nous penser que les manuscrits coraniques pouvaient être utilisés pour apprendre le Coran et les lectures coraniques au moyen de la copie, d'autant plus qu'ils pouvaient être empruntés ${ }^{130}$.

Parallèlement à leurs fonctions publiques, les manuscrits coraniques jouaient aussi un rôle dans la sphère privée. Ainsi, au même titre qu'offrir, commander ou lire un coran au profit d'une institution publique, copier le texte saint est un acte de dévotion privée auquel se sont d'ailleurs adonnés quelques têtes couronnées, comme le vizir (hâjjib) et régent du calife umayyade de Cordoue al-Manșūr (r. 976-1002), le calife almohade al-Murtaḍā (r. 1248-1266), le sultan mérinide Abū'l-Ḥasan (r. 1331-1348) ou le prince de Tlemcen Abū Zayyān Muhammad (en 801/1398) ${ }^{131}$. De même, quelques manuscrits coraniques sont associés à des événements familiaux, en particulier des naissances, et ce dans divers milieux sociaux, comme le montrent deux corans commandés à l'occasion de la naissance pour le premier d'un prince héritier, pour le second d'un inconnu ${ }^{132}$. Dans ce cas, le manuscrit coranique a vraisemblablement la valeur d'un ex voto, produit et offert dans le but de louer Dieu, de le remercier pour la naissance, mais possède aussi une fonction prophylactique et apotropaïque pour la descendance du mécène. Les muṣhafs de petite taille pouvaient être des copies personnelles, transportables, et quelques corans miniatures, de moins de $10 \mathrm{~cm}$ de côté, pouvaient aussi être utilisés comme des talismans ${ }^{133}$, ce qui montre la diversité des rôles joués par les manuscrits coraniques dans la piété de l'Occident musulman.

Pour conclure, nous pouvons affirmer que les recherches sur les corans et en particulier les manuscrits coraniques de l'Occident musulman médiéval ont, ces dernières années, connu des avancées considérables. Ainsi, dans le grand flou du « coufique " commencent à poindre 
quelques pistes permettant d'identifier les muṣhafs proprement occidentaux. De même, on a désormais une idée plus précise et des hypothèses très prometteuses sur la question de l'origine, de la diffusion et de l'évolution du Maghribī. Les travaux sur les divers aspects codicologiques des manuscrits hispano-maghrébins se multiplient et sont d'un niveau d'exigence beaucoup plus élevé en termes de connaissances techniques, par exemple des papiers, des pigments ou des reliures.

Ces travaux fourniront des outils très utiles pour guider les grands chantiers à venir, en particulier le catalogage des collections qui ne le sont pas encore, la création de bases de données transversales, et le développement de projets systématiques du type du projet Corana. Ces recherches permettront de mieux comprendre les spécificités régionales et historiques et de répondre aux nombreuses questions encore ouvertes. Par exemple, comment expliquer l'émergence d'une spécificité occidentale dans les manuscrits coraniques au $\mathrm{X}^{\mathrm{e}}$ siècle ? Cette évolution est-elle liée à un changement soudain ou progressif dans les instruments de l'écriture ? Quel est le rôle des communautés non musulmanes et non arabes ? Pourquoi le Maghribī ne se diffuse-t-il pas sur les objets d'art et dans le décor architectural ? Comment l'écriture se développe-t-elle après la Reconquista, aussi bien en Espagne, dans les manuscrits aljamiados, que dans le Maghreb ? Qu'en est-il de l'utilisation du Livre saint après la période médiévale? Le fait que ce champ de recherche attire à la fois de grands savants et de jeunes chercheurs particulièrement brillants laisse entrevoir de belles perspectives. 


\section{Notes}

1. Pour une synthèse récente sur l'histoire de la compilation et de la transmission du Coran, voir DÉROCHE, 2005.

2. HUMBERT, 2002, p. 7.

3. GEORGE, $2015 a$, p. 1.

4. Les plus anciens manuscrits datés ou datables remontent au deuxième quart du III /IX siècle, dont un coran constitué waqf ou habūs par une princesse aghlabide, Khadīja bint al-Aghlab (De Carthage à Kairouan..., 1982-1983, no 321, p. 245 ; Tunisie : du christianisme à l'Islam, 2001, $\mathrm{n}^{\circ}$ 117). Voir aussi Déroche, 1989 ; DÉROCHE, $2001 \mathrm{a}$, p. 594 ; RAMMAH, 2009, p. 3, 4 .

5. Sur l'inventaire de 693/1293, voir CHАВВОUн, 1956 ; GACEK, 1989 ; VOGUET, 2003 ; DÉROCHE, 2008 ; DÉROCHE, 2010. Sur le fonds aujourd'hui, voir BUHLī AL-NAYYĀL, 1953 ; 'ABD AL-WAHHĀB, 1955 ; BUHLİ AL-NAYYĀL, 1963 ; The Arts of Islam, 1976, n 501 503, 505-507 ; De Carthage à Kairouan..., 1982-1983, p. 232-275 ; DÉROCHE, 1999, passim; Tunisie : du christianisme à l'Islam, 2001, n¹11-121 ; DÉROCHE, 2008, p. 248 ; RAMMAH, 2008 a et b.

6. LUCCIONI, 1955, passim., surtout p. 236-239, 244-245 ; ROPER, 1991 -, vol. 1, p. 58-61 ; BINEBINE, 2000, p. 9194, 210-211; MANŪNĪ, 2005, p. 57-63- ; ENNAHID, 2011, p. 267.

7. Sur ces bibliothèques, voir en particulier ZAYTŪNIYYA, 1884 ; CODERA, 1888 ; ROPER, 1991-, passim ; LUCCIONI, 1955. p. 239-240 ; BINEBINE, 2000, p. 94-95, 122 ; MANŪNĪ, 2005.

8. ROPER, 1991-, vol. 4, p. 1-34; BOUTERFA, 2005 ; ABDELHAMID, 2006 ; SCHEELE, 2011.

\section{Chabbouh, 1989 ; CheikHa, 2008.}

10. De cette bibliothèque qui était estimée à plusieurs milliers, voire centaines de milliers de volumes, il ne reste qu'un manuscrit (LÉVI-PROVENÇAL, 1934). Un autre fonds ancien important a été envoyé par un souverain espagnol au sultan mérinide Abū Yūsuf Ya qūb (r. 1258 1286) qui l'a déposé à la madrasa Șaffārīn en 1285. Ce fonds a probablement ensuite été transféré à la Qarawiyyīn (LUCCIONI, 1955, p. 237 ; BINEBINE, 2000, p. 93).

11. BINEBINE, 2000, p. 148-149, et 2004, p. 172-186.
12. Sur cette production, voir en particulier les travaux de María José Hermosilla Llisterri, Consuelo López-Morillas et Nuria Martínez de Castilla.

13. Manuscrits arabes..., 1990 ; HeNDRICKSON, 2008. Sur les manuscrits arabes en Espagne, voir en particulier Viguera Molins, FANJUl GARCÍA, 2016.

14. Voir par exemple le bi-feuillet du Coran de la Nourrice acquis par la Collection David en 2003 (inv. 25/2003, http://www.davidmus.dk/en/collections/ islamic/materials/calligraphy/art/252003 [consulté le 13 juin 2017]) ; le bi-feuillet acquis par le Metropolitan Museum of Art de New York en 2007 (inv. 2007.191, http://www.metmuseum.org/art/collection/search/456074 [consulté le 12 juin 2017]).

15. ENNAHID, 2011 , p. 287-288 ; BOUJDAD MKADEM, NieUWENHUYSEN, 2012, p. 70.

16. Sur les catalogues des collections marocaines, voir BINEBINE, 2004, p. 42-78. Sur l'Algérie, SCHEELE, 2011, p. 293-294.

17. ARIAS TORRES, DÉROCHE, 2011.

18. Par exemple le titre "al-Qitāl " pour la sourate 47 , " al-Qalam " pour la sourate 96, ou "Zulzilat " pour la sourate 99.

\section{ESPEJO, BENY, 2008.}

20. ESTÈVE, 2001 a, p. 48.

21. ESTÈve, 2001 a et 2003 ; Espejo, BENY, 2008, entrée 3.5.1.5.

22. ESTÈVE, 2001 b, p. 48.

23. ESTÈVE, $2001 \mathrm{lb}$; ESPEJO, BENY, 2008, entrée 3.5.1.3, et surtout 3.5.1.3.3 et 3.5.1.3.4.

24. ESPEJO, BENY, 2008, entrée 3.6.2.1.3. Le protocole d'Espejo et Beny présente un autre avantage. Il est accompagné d'un glossaire espagnol/français/anglais et parfois arabe qui lui permet d'être utilisé dans ces différentes langues.

25. Le FiMMOD comporte quelques manuscrits de l'Occident musulman décrits notamment par Marie-Geneviève Guesdon. De plus, il s'agit d'un fichier papier qui n'est consultable que dans les salles du département des Manuscrits de la BnF et à la bibliothèque de l'IRHT à Paris ; un projet de numérisation est cependant en cours.

26. Les deux chercheurs ont organisé plusieurs journées d'études (JAOUHARI, 2013a, 2015 ; Mustapha Jaouhari (dir.),
"Naissance et genèse de l'écriture mag̉ribī ", journée d'études, Rabat, CJB, 27 novembre 2014 ; Idem, " Histoire et paléographie des écritures arabes d'alAndalus ", journée d'études, Rabat, CJB, 17 décembre 2015 ; Nuria Martínez de Castilla (dir.), " Transmission et usage du Coran ", journée d'études, Paris, 22 mars 2013 ; et Eadem, "Regards croisés sur le Coran en al-Andalus et au Maghreb ", colloque, Madrid, 15-16 décembre 2014 ; Nuria Martínez de Castilla et François Déroche (dir.), "Le texte coranique et son contexte : le cas de l'Occident musulman (XI ${ }^{\mathrm{e}}-\mathrm{XVIII}^{\mathrm{e}}$ s.) ", journée d'études, Paris, Collège de France, 7 décembre 2015, mais seules les deux premières ont été publiées à ce jour.

27. Islamic Seals Database, 2017.

28. ENNAHID, 2011 , p. 273-274.

29. JAOUHARI, 2013a, p. 19 ; JAOUHARI, 2015, p. 26, n. 4.

30. BOUJDAD MKADEM, NIEUWENHUYSEN, 2012 .

31. Voir ci-dessus, n. 26.

32. Michele Amari identifie "une écriture du i iden " en se basant notamment sur la remarque d'Ibn al-Nadīm à propos des "premières écritures de La Mecque et de Médine " (Michele Amari, Catalogue des manuscrits arabes de la Bibliothèque nationale, Paris, Bibliothèque nationale de France, manuscrit Arabe 4499, remarques reprises par William Mac Guckin, à partir de M. le Baron de Slane, Catalogue des manuscrits arabes, Paris, 1883-1895, p. 87-117; François Déroche, "La paléographie des écritures livresques dans le domaine arabe ", dans la Gazette du Livre Médiéval, nº 28, 1996, p. 3). Parmi les caractéristiques générales du groupe Hijāzī figurent l'emploi du format vertical, à la française, de relativement grandes dimensions (supérieures à $20 \times 30 \mathrm{~cm}$ ), de différentes qualités de parchemin et de différents systèmes d'assemblage des cahiers ou de réglure, la scriptio continua, la non notation de la hamza ('), des variantes dans la notation de la voyelle longue " $\bar{a}$ ", des hampes inclinées à droite. Sur ce groupe, voir en particulier DÉROCHE, 1983, p. 35-36, 5964 ; DÉROCHE, 1992, p. 27-33 ; GEORGE, 2010a, p. 31-53.

33. DÉROCHE, 1989, p. 352.

34. DÉRoche, 2009, p. 113.

35. DÉROCHE, 1989, p. 353. 


\section{DÉROCHE, 1989, p. 352-353.}

37. Ce dont Déroche lui-même est évidemment conscient : DÉROCHE, 1983, p. 15-16; DÉROCHE, 1989, p. 351 ; DÉROCHE, 1999, p. 234.

38. DÉROCHE, 2001 a, p. 594.

39. DÉROCHE, 2001 a, p. 595, n. 6.

40. Raqqāda, Musée des arts islamiques, et feuillets dispersés. Voir Chаввочн, 1956, n 1 ; De Carthage à Kairouan..., 1982-1983, n 350 ; BLOOM, 1986 ; BLOOM, 1989 ; DÉROCHE, 1992, nº 42 ; Itinéraire du savoir en Tunisie..., 1995, p. 48 ; Neumeier, 2008 ; GeORGe, 2010b ; BLOOM, 2015.

41. Seule une poignée d'autres corans bleus sont connus, mais ceux-ci sont en papier, et beaucoup plus tardifs, par exemple un coran mérinide (BNRM, 1304 D, voir Splendeurs de l'écriture au Maroc..., 2017, p. 38-39) et un coran indien de 1099/1687-1688 (Christie's, 09 octobre 2014, lot 6).

42. La lettre $h \bar{a}^{\prime}[\mathrm{H}]$ dont la valeur numérique est cinq pour les groupes de cinq versets et d'autres lettres pour les groupes de dix versets qui sont comptés dix par dix ; d'autres décors argentés ont été ajoutés dans un second temps.

43. En raison de sa couleur bleue qui a été associée au deuil et donc au tombeau d'un calife : Hārūn al-Rashīd (786-809 ; MARTIN, 1912; The Arts of Islam, 1976, $\left.\mathrm{n}^{\circ} 498\right)$.

44. En raison de sa somptuosité (The Arts of Islam, 1976, $\mathrm{n}^{\circ} 498$ ) ou pour des critères historiques et paléographiques plus solides. En effet, il existe deux systèmes alphanumériques ou abjads différents. Le premier est utilisé aux premiers temps de l'Islam, au VIII et probablement encore au IX ${ }^{e}$ siècle. Ensuite, cet abjad perdure dans l'Occident musulman, mais un autre apparaît en Orient au milieu du IX siècle. Or, le Coran bleu emploie le système ancien et/ou occidental. De plus, il est calligraphié en D. IV, un style qui peut-être daté de la seconde moitié du VIII ${ }^{\mathrm{e}}$ - première moitié du IX ${ }^{\mathrm{e}}$ siècle, comme d'autres traits orthographiques et phonétiques. Enfin, l'écriture dorée sur fond bleu est comparable à plusieurs réalisations architecturales de l'âge d'or abbasside. George en conclut que ce coran est vraisemblablement une commande royale de l'âge d'or abbasside, transportée ensuite vers la Tunisie des Aghlabides (GEORGE, 2010b).
45. Principalement en raison de sa conservation à Kairouan (BLOOM, 1986 et 1989).

46. Par comparaison avec l'évangéliaire de Rossano, en Calabre (FRASER, KWIATKOWSKI, 2006).

47. Surtout par comparaison avec les mosaïques de la Grande Mosquée de Cordoue (STANLEY, 1995, p. 7-15).

48. Plusieurs centaines de feuillets conservés à Raqqāda et quatre à Paris (BnF, Arabe 5178m, fol. 18-21). Voir 'ABD ALWAHнĀB, 1934, p. 30-31; СНАВBOUH, 1956, p. 339, pl. 1b ; De Carthage à Kairouan..., 1982-1983, p. 240; DÉROCHE, 1983, no 197 ; RAMMAH, 2009, p. 3, 4 ; GEORGE, 2015b, p. 75-77, fig. 1. Les feuillets de la BnF sont numérisés : http://gallica.bnf.fr/ark:/12148/ btvlb8419227g/f54.image.r=Arabe $\% 20$ 5178 (consulté le 13 juin 2017).

49. Raqqāda, Musée des arts islamiques, $n^{\circ}$ 23, voir 'ABD AL-WAHнĀB, 1934, p. 39-44; The Arts of Islam, 1976, n' 501 ; De Carthage à Kairouan..., 1982-1983, n 328 ; DÉROCHE, 1999, p. 236-237; Tunisie : du christianisme à l'Islam..., 2001, nº 113, pl. 16, 18 ; RAMMAH, 2009, p. 17.

50. Raqqāda, Musée des arts islamiques. La rupture avec les fatimides est explicitée au moyen de l'expression de la haine (bughd) que le prince voue à la dynastie chiite dans l'acte de habūs. Voir The Arts of Islam, 1976, n 502; De Carthage à Kairouan..., 1982-1983, n 330 ; Itinéraire du savoir en Tunisie..., 1995, p. 45; DÉROCHE, 2001 a, p. 595 ; Tunisie : du christianisme à l'Islam..., 2001, nº 120 ; DÉROCHE, 2005, p. 250, 252 ; RAMMAH, 2008a, p. 19 et 2009, p. 21, 22.

51. Istanbul, Türk ve Islam Eserleri Müzesi (ci-après TIEM), ŞE 9655, voir DÉROCHE, 1999, p. 237.

52. Istanbul, Mosquée Nurosmaniye, $\mathrm{n}^{\circ} 23$, et deux cahiers à Londres, Collection Nasser D. Khalili, QUR 261 et 368. Le colophon est inscrit dans le frontispice, au fol. $1 v^{\circ}$. Voir DÉROCHE, 1992, nº 81 ; DÉROCHE, 1999, p. 238 ; DÉROCHE, 2001 a, p. 596-604 ; GEORGE, $2010 a$, p. 142-143, fig. 71 et $71 \mathrm{~b}$; GEORGE, 2015b, p. 77-81, fig. 2-6.

53. Raqqāda, Musée des arts islamiques, $\mathrm{n}^{\circ} 361$ et feuillets dispersés (supra). Voir 'ABD AL-WAHHĀB, 1934, p. 47-49; MARÇAIS, POINSSOT, 1952, p. 310-311, fig. 16 ; Снаввочh, 1956, pl. la ; De Carthage à Kairouan..., 1982-1983, p. 204,
272-273, no 356, 357 ; Itinéraire du savoir en Tunisie..., 1995, p. 9 ; DÉroche, 1999, p. 238 ; DÉROCHE, 2001a, p. 606-608, fig. 7 ; Tunisie : du christianisme à l'Islam..., 2001, no 114, pl. 17 ; BLAIR, 2006, p. 154156 ; RAMMAH, 2008a, p. 17 et 2009, p. 19.

54. Apparemment, un seul feuillet est conservé. Voir 'ABD AL-WAHHĀB, 1934, p. 45-47.

55. Ceci est aussi le cas de quelques autres corans dépourvus de colophon : un coran oblong et un coran vertical à Raqqāda (De Carthage à Kairouan..., 1982 1983, no 359 et 360 ; RAMMAH, 2009, p. 18), et un autre coran vertical à la BNRM (1 G, voir MANŪNĪ, 1991, p. 41 ; Splendeurs de l'écriture au Maroc..., 2017. p. 36). Sur le Nouveau Style, voir en particulier DÉROCHE, 1983, p. 136-142 ; DÉROCHE, 1992, p. 132-183; GEORGE, 2010, p. 160-161.

56. GEORGE, 2015b, p. 77, 97.

57. BONGIANINO, 2017, p. 22. Je remercie Mr. Bongianino de m'avoir envoyé une copie de sa thèse qui n'est pas encore publiée.

\section{DUtTON, 1999 et 2000.}

59. Londres, Collection Khalili, QUR 372 , voir DÉROCHE, 1992, nº 24.

60. Les décors jouent principalement sur le contraste de l'or et du parchemin et présentent des formes analogues : nūn à queue montante dans les titres des sourates; marques de versets en forme de rosette simple (type 3.1.1); groupes de dix versets en forme de fleur à gros pétales, avec un élément circulaire et une ponctuation à l'extérieur (type 3.C.II) ; vignettes lancéolées avec décor de rinceau. Voir DÉROCHE, 1983, p. 49, 98-99 ; DÉROCHE, 1992, p. 37, et surtout 2001a, p. 605-606.

61. GEORGE, 2015a et surtout GEORGE, 2015b.

62. GEORGE, 2015b, p. 95-96. Le tanwīn est le fait de prononcer une lettre ou un mot avec la lettre $n \bar{u} n(\mathrm{~N})$. La hamza est la lettre '. La șila indique que la hamza ne doit pas être prononcée. Le sukūn marque l'absence de voyelle. La ponctuation du $f \bar{a}^{\prime}$ avec un point en dessous et du qāf avec un point au-dessus continue au Maghreb jusqu'au XIX ${ }^{\text {e }}$ siècle (BONGIANINO, 2017, p. 18).

63. GEORGE, 2015 b, p. $83,85$.

64. GEORGE, 2015b, p. 82, 90, 92, 96. 
65. JAOUHARI, 2013a, p. 20. BONGIANINO, 2017, passim.

66. Seul le feuillet du colophon est conservé : Istanbul, TIEM, ŞE 13644/1, voir DÉROCHE, 1991, p. 231-232, fig. 2 ; BONGIANINO, 2017, Q2, passim.

67. GEORGE, 2015b, p. 86.

68. MANŪNĪ, 1991, 13, 47 ; BARRUCAND, 1992, p. 236.

69. BOngIANino, 2017 , p. 1. Il faut cependant noter que la première référence au Maghribī serait dans ce cas antérieure d'environ un siècle et demi aux premières attestations connues de ce style. La notion d' " écriture maghrébine " est donc vraisemblablement plus tardive.

70. VAN DEN BOOGERT, 1989 ; D'OTTONE, 2013, p. 7-8; BONGIANINO, 2017, p. 14.

71. BONGIANINO, 2017, p. 15-16.

72. HOUDAS, 1886 ; BARRUCAND, 1992 p. 236 ; DÉROCHE, 1994, p. 77 ; BINEBINE, 2000, p. 185 ; MANŪNĪ, 2005, p. 40 ; ENNAHID, 2011, p. 271.

73. LINGS, 1961, p. 96 ; MANŪNĪ, 2005 , p. 40, quoi que ce passage montre une grande confusion entre "coufique", " maghrébin " et " andalou " qui sont présentés comme des synonymes. Voir aussi BONGIANINO, 2017, p. 2-3, 167-168.

74. DÉROCHE, 1999, p. 239-241; D'OtTONe, 2013 ; JAOUHARI, $2013 \mathrm{a}$, p. 22 ; BONGIANINO, 2015, p. 12, n. 30 , p. 17 , n. 42 ; BONGIANINO, 2017, passim.

75. DÉROCHE, 1991, p. 233.

76. Istanbul, TIEM, ŞE $13216 / 1$, voir DÉROCHE, 1991, p. 230-231, fig. l ; DÉROCHE, 1999, p. 240, et 2001a, p. 595; BONGIANINO, 2017, Q1.

77. DÉROCHE, 1989, p. 364 ; BONGIANINO, 2017, p. 15-16.

78. DÉROCHE, 1999, p. 243.

79. DÉROCHE, 1989, p. 364-365, et 1991, p. 233, et 1999, passim et p. 243-244.

80. BONGIANINO, 2017, p. 11, 16-20.

81. D'Ottone, 2013. À l'encontre de l'hypothèse de D'Ottone, Adriaan Keller remarque que " les techniques des manuscrits arabo-maghrébins ne coïncident pas du tout avec celles des manuscrits visigotiques ». En revanche, les manuscrits " arabo-maghrébins " chrétiens présentent des caractéristiques communes avec les manuscrits " arabo-maghrébins " musulmans (KELLER, 1985, p. 16).
82. BONGIANINO, 2017.

83. Respectivement Fès, Qarawiyȳin, n 605 (BINEBINE, 2004, p. 191 ; JAOUHARI, 2013a, p. 20, fig. 2 ; BONGIANINO, 2015, p. 12 ; BONGIANINO, 2017, p. 28 , n. 116 , item 39, passim), et Istanbul, Topkapı Sarayı Müzesi Kütüphanesi (TSMK), R. 27 (BONGIANINO, 2017, Q16).

84. BONGIANINO, 2017, p. 27.

85. Seul le quatrième volume est conservé, à Londres, British Library, Ms. Add. 11638 . Il est signé par Muhammad b. Hasan b. Ahmad al-Azdī. Voir DANDEL, 1999, p. 253 ; BONGIANINO, 2017, p. 3-4.

86. BongIANINO, 2015 , p. 12 et 2017 , p. 22, n. 93 .

\section{DÉROCHE, 2010 b.}

88. Ces attributions apparaissent avec plus ou moins d'esprit critique par exemple dans HOUdAS, 1886 ; VAN KONINGSVELD, 1976, p. 26-28; MANŪNII, 1991, p. 1314, 47 ; BINEBINE, 2000, p. 186 ; AFĀ, MAGHRĀWĪ, 2007 ; ENNAHID, 2011 , p. 271-272.

\section{JAOUHARI, 2013a.}

90. JAOUHARI, 2015.

91. JAOUHARI, 2015, p. 44.

92. Manuscrit signé par un copiste de Rayy ('Alī b. Shādhān al-Rāzī), dispersé (Dublin, Chester Beatty Library, $\mathrm{n}^{\circ} 1434$; Istanbul, Bibliothèque de l'Université, A6758 ; Ardabil, Mausolée de Shaykh Șafī), voir TABBAA, 1991, p. 127-130, fig. 8-9.

93. Une référence textuelle mentionne un fabricant de parchemin et de papier kairouanais à la cour du calife umayyade de Cordoue, al-Hakam II (BongIANINO, 2017, p. 27, n. 113). L'un des premiers exemples de manuscrit complet en papier occidental est un ouvrage de droit malikite réalisé pour al-Ḥakam II en 359/970 (Fès, Qarawiyyīn, nº 874, voir BONGIANINO, 2017, p. 21, 26-27, 35-36). Des cahiers mixtes de parchemin et de papier apparaissent dans les manuscrits kairouanais dès le début $\mathrm{du} \mathrm{XI}^{\mathrm{e}}$ siècle (DÉROCHE, 2000, p. 58, 90, n. 52).

94. Par exemple un coran de petites dimensions $(8 \times 7 \mathrm{~cm})$ copié à Almeria en 534/1139 (Madrid, Biblioteca Nacional de España, RES/272, voir BONGIANINO, 2017, Q5).

95. BOngIANINO, 2017, passim. Selon Rodriguez Diaz, D'Ottone et Bongianino, l'emploi tardif du parchemin, tout comme quelques autres caractéristiques codicologiques, en particulier le respect de la règle de Grégory et le choix du quaternion, pourraient aussi s'expliquer par la proximité de la tradition technique latine (RODRIGUEZ DIAZ, 2011 ; D'OTTONE, 2013, p. 14 ; BONGIANINO, 2017, p. 54). Cependant, il me semble que cette hypothèse mérite d'être testée sur un corpus plus important.

96. BONGIANINO, 2017, p. 54.

97. 1. Coran en 20 volumes, Malaga, 60/1223, puis déposé à la mosquée Kutubiyya (Marrakech, Bibliothèque Benyoussef, $\mathrm{n}^{\circ} 430$, voir Maroc médiéval..., 2014-2015, $\left.\mathrm{n}^{\circ} 211\right)$. 2. Coran en 4 volumes, $48 \times 59 \mathrm{~cm}$, offert par le prince almohade Ibrāhīm b. Abī Ibrāhīm b. Abī Ya 'qūb à une mosquée de Marrakech en 635/1238 (Istanbul, TSMK, R. 2124). 3. Coran en 20 volumes, Séville, $632 / 1235$, offert par le calife almohade al-Murtaḍa au mausolée dynastique à Tinmal en 649/1251 (Marrakech, Bibliothèque Benyoussef, $\mathrm{n}^{\circ} 429$, voir Maroc médiéval..., 2014-2015, n²12). 4. Coran en 10 volumes calligraphié par le calife almohade al-Murtaḍā en 654/1256 (Marrakech, Bibliothèque Benyoussef, no 432 ; Rabat, BNRM, n 1278 ; Londres, British Library, Or. 13129, voir RICARD, 1933, p. 110-117 ; MANŪNĪ, 1991, p. 3637, 39 ; BINEBINE, 2000, p. 144, 221 ; Maroc médiéval..., 2014-2015, n² 218-222 ; BONGIANINO, 2017, p. 120, 139, 140-145).

98. De nombreux exemples au XIV siècle, par exemple un coran réalisé pour la bibliothèque (khizāna) du souverain mérinide Abū Ya'qūb Yūsuf probablement à Fès en 705/1306 (Munich, Bayerische Staatsbibliothek, cod. arab. 2 et 3, voir BARRUCAND, 1992, p. 236, 242, fig. 7-11); le premier coran en Maghribī ifrīqiyyen réalisé à Tunis en 706/1306 (supra); plusieurs exemples publiés, par exemple dans MeHrez, 1955 ; SIJELMASSI, 1987, p. 48-49, 55.

99. BONGIANINO, 2017, p. 120-121.

100. BineBine, 2000, p. 212.

101. Sur les papiers de l'Occident musulman, voir en particulier VALLS I SUBIRÀ, 1978 ; ESTÈVE, $2001 \mathrm{la} ; 2001 \mathrm{~b}$ et 2004 ; BRINQUIS, CARMEN, 2008 ; ACTAS, 2011 ; ESTÈVE, 2015.

\section{BONGIANINO, 2017, Q3.}

103. DÉroche, 2001 a, p. 610-620; BONGIANINO, 2017, Q5 à Q24. 
104. DÉROCHE, 2001 a, p. 613.

105. BONGIANINO, 2017, p. 144-146.

106. Dans l'inventaire de Kairouan, seuls trois corans sont des volumes uniques, et Déroche a pu estimer l'ensemble à plus de mille unités codicologiques (DÉROCHE, 2008, p. 249, 251).

107. Paris, BnF, Arabe 389 à 392 et Bibliothèque nationale de Russie, voir DÉROCHE, 1985, n 305-308; Itinéraire du savoir en Tunisie..., 1995, p. 48-49; DÉROCHE, 2005, p. 252. Pour un autre manuscrit, de Hadīth, offert par le même sultan à la Grande Mosquée de Kairouan, voir RAMMAH, 2009, p. 23. Ce souverain a aussi déposé toute une bibliothèque dans la Zītūna en 1394-1395.

108. BINEBINE, 2000, p. 211 ; DÉROCHE, 2005, p. 252

109. DÉROCHE, 2001 a, p. $615 ; 2001$ b et 2008, p. 250.

110. DÉROCHE, 1983, p. 23-33, 49-51 ; BARRUCAND， 1992 ; DANDEL， 1993 ; DANDEL, 1994 ; BARRUCAND, 1995 ; DANDEL， 1999 ; DÉROCHE, 2001 a ; GLADISS, 2004 ; BARRUCAND, 2005.

111. LiNGS, 1961 ; CHABBOUH, 1989 , $\mathrm{n}^{\circ} 1,2$; BARRUCAND, 1992, p. 238 239, n. 8 ; DANDEL, 1993 ; Itinéraire du savoir en Tunisie..., 1995, p. 46-47; Maroc médiéval..., 2014-2015, n² 208, 209 ; BONGIANINO, 2017, p. 149-158.

112. BONGIANINO, 2017, p. 140-143.

113. DANDEL, 1999, p. 252.

114. Sur les pigments employés dans les manuscrits de l'Occident musulman, voir GUINEAU, 2000 ; ROGER, SERGHINI, DÉROCHE, 2004 ; BONGIANINO, 2017. p. 108-109.

115. BONGIANINO, 2017, p. 70.

116. MARÇAIS, POINSSOT, 1952 ; voir aussi The Arts of Islam, 1976, $\mathrm{n}^{\circ}$ 505-507 ; De Carthage à Kairouan..., $1982-1983$, p. 232-239 ; DÉROCHE, 2000, p. 278 326 ; RAMMAH, 2008a, p. 22-24 et 2009, p. 30-31.

117. Pour d'autres exemples et études sur des reliures plus tardives, voir RICARD, 1933 et 1934.

118. SCHEPER, 2014 ; GONZALES GARCIA, 2014 ; BENY, 2015.

119. 'Umdat al-Kuttāb..., 1971, traduction française : ABARROU, 2015 ; GACEK, 1991 ; SUFYĀNĪ, 1925.
120. Dessus-LAMARe, 1938 ; Déroche, 1999, p. 235 ; BINEBINE, 2000, p. 211 ; MANŪNI, 2005, p. 82 ; BENNISON, 2007 ; BURESI, 2008 ; ZADEH, 2008 ; BONGIANINO, 2017, p. 89, 140, 145.

121. DeSSUS-LAMARE, 1938, p. 555.

122. Ibidem.

123. Il s'agit probablement du manuscrit conservé à Istanbul, au palais de Topkapı, E. H. 44 (BINEBINE, 2000, p. 211-212; BONGIANINO, 2017, p. 89, n. 114).

124. Dessus-LAMARE, 1938 , p. 569 ; BONGIANINO, 2017, p. 145.

125. Dessus-LAMARE, 1938 , p. 558, n. 2 , p. 566 ; GEORGE, 2010b, p. 98, 100.

126. À côté des exemples mentionnés ci-dessus, voir le coran en un volume réalisé par à 'Abdallah b. Muhammad b. Ghațtūs pour le vizir Abū Muhammad 'Abdallah b. 'Abd al-Rahmān b. 'Abdallah al-Madhḥijī al-Lawshī à Valence en 557/1161-1162 (Le Caire, Dār al-Kutub, Muṣhaf 196, voir BARRUCAND, 1992, n. 8 ; DANDEL, 1993 ; BONGIANINO, 2017, Q8). Pour des exemples de corans royaux plus tardifs, voir BINEBINE, 2000, p. 212. Pour des corans commandés par des " inconnus », BONGIANINO, 2017, Q9 et Q21.

127. GEORGE, $2010 a$, p. 86 , et 2010 b, p. 100.

128. DÉROCHE, 2005, p. 254. Des indications beaucoup plus précises sont disponibles à l'époque ottomane (ERGIN, 2008 et 2013).

129. Bongianino, 2017, p. 153, fig. 41. Sur la question de l'utilisation des manuscrits coraniques pour l'enseignement, voir aussi DÉROCHE, 2008, p. 253.

130. BINEBINE, 2000, p. 144-145.

131. Respectivement 1. BongIANINO, 2017, p. 89. 2. Supra, n. 96. 3. DessusLAMARE, 1938, p. 575 ; MANŪNĪ, 1991 , p. 61; Maroc médiéval..., 2014-2015, p. 464-467. 4. BINEBINE, 2000, p. 213 . Le coran continue d'ailleurs à être copié à la main jusqu'à aujourd'hui.

132. Le prince Abū Ya'qūb, fils et héritier du calife almohade al-Nāṣir (r. 595-610/1199-1213), en 599/1203, et un certain Abū 'Abdallah Muḥammad b. 'Alī b. Muḥammad b. Yaḥyā al-Ghāfiqī al-Shārī à Murcie. Ce coran a été réalisé à Cordoue en 537/1143. (BONGIANINO, 2017, Q24 et Q6 ; voir aussi LINGS, 1961 ; BONGIANINO, 2017, p. 153, n. 284).

133. BONGIANINO, 2017, p. 153. 


\section{Bibliographie}

- AbARrou, 2015 : Jamâl Abarrou, L'Art du livre et sa fabrication au XI' siècle en occident musulman et en Europe du sud : encres, papier, colles, enluminure, reliure et calligraphie. Le livre de soutien aux scribes et le matériel des initiés, "Umdat al-kuttāb wa 'uddat dawī al$a l b \bar{a} b$ ", La Plaine Saint-Denis, 2015.

- 'ABD AL-WAHHĀB, 1934 : Ḥasan Ḥusnī 'Abd al-Wahhāb, Shahīrāt al-tūnisiyyāt, Tunis, 1353/1934.

- 'ABD AL-WAHHĀB, 1955 : Ḥasan Ḥusn̄̄ 'Abd al-Wahhāb, " Al- 'ināya bi'l-kutub wa-jam uhā fī ifrīqiyya al-tūnusiyya min al-qarn al-thālith ilā al-khāmis li'l-hijra ", dans Majallat Ma'had al-Makhtūtât al'Arabiyya, v 1.1, 1955, p. 72-90.

- 'ABD AL-WAHHĀB, 1956 : Ḥasan Huusnī 'Abd al-Wahhāb, " Al-Bardī wa al-riqq wa al-kāghadh fĩ Ifrīqiyya al-tūnusiyya ", dans $M M M A, \mathrm{n}^{\circ} 2.1,1956$, p. 34-45, réimprimé dans 'Ilm al-makhțūt al-'arabī : buhūth wa dirāsāt, Koweït, 1435/2014, p. 161-176.

- ABDelHamid, 2006 : Arab Abdelhamid, Manuscrits et bibliothèques musulmanes en Algérie, Méolans-Revel, 2006.

- Actas de la reunión..., 2011 : Actas de la reunión de estudio sobre el papel hispanoárabe, actes du colloque (Xàtiva, 2009), Valence, 2011 [en ligne, URL : http://fr.calameo. com/read/000692387a86e33c27bba (consulté le 30 juin 2017)].

- AFĀ, 2013 : 'Umar Afā, "Al-khațt almaghribī wa adawāt intājih ", dans JAOUHARI , 2013, p. 71-78.

- AFĀ, MAGHRĀWĪ, 2007 : 'Umar Afā, Muḥ ammad al-Maghrāwī, Al-khatṭ al-maghribī. Tārīkh wa wāqi 'wa āfāq, Rabat, 2007.

- ARIAs Torres, Déroche, 2011 : Juan Pablo Arias Torres, François Déroche, "Reflexiones sobre la catalogación de ejemplares alcoránicos (a propósito del ms. 1397 de El Escorial) ", dans Al-Qantara, no 32.1, 2011 , p. 243-260.

- The Arts of Islam, 1976 : The Arts of Islam, cat. exp. (Londres, Hayward Gallery, 1976), Londres, 1976.

- AZZAWI, JAmes, 2010 : Diyā al-Azzāwī, David James, Manuscripts of the Holy Qur'an from the Beginning to the Fall of Baghdad, H656, AD1258, vol. 1, St. Helier, 2010.

- BARRUCAND, 1992 : Marianne Barrucand, "Remarques sur le décor des manuscrits religieux hispano-maghrébins du Moyen Âge ", dans Afrique du Nord antique et médiévale : spectacles, vie portuaire, religions, actes du colloque (Avignon, $5^{\mathrm{e}}$ Colloque international sur l'histoire et l'archéologie de l'Afrique du Nord), Paris, 1992, p. 235-248.
- BARRUCAND, 1995 : Marianne Barrucand, "Observaciones sobre las iluminaciones de Coranes hispano-magrebies", dans Arte Islámico en Grenada: propuesta para un Museo de la Alhambra, cat. exp. (Grenade, Palacio de Carlo V, La Alhambra), Grenade, 1995, p. 161-171.

- BARRUCAND, 2005 : Marianne Barrucand, "Les enluminures de l'époque almohade : frontispices et 'unwāns ", dans Patrice Cressier, Maribel Fierro et Luis Molina (dir.), Los Almohades: problemas y perspectivas, Madrid, 2005, vol. 1, p. 71-121.

- BenJelloun-Laroui, 1990 : Latifa Benjelloun-Laroui, Les bibliothèques au Maroc, Paris, 1990.

- Bennison, 2007 : Amira K. Bennison, "The Almohads and the Qur'ān of 'Uthmān. The Legacy of the Umayyads of Cordoba in the Twelfth-Century Maghrib ", dans Al-Masāq, n 19.2, 2007, p. 131-154.

- Beny, Espejo ARIAs, ARIAs Torres, 2015 : Ana Beny, Teresa Espejo Arias, Juan Pablo Arias Torres, "Andalusi Binding: a Model of Islamic Binding from the Iberian Peninsula, 14th-16th Century ", dans Journal of Islamic Manuscripts, $\mathrm{n}^{\circ} 6$, 2015, p. 157-173.

- Binebine, 2000 : Ahmed-Chouqui Binebine, Histoire des bibliothèques au Maroc, Rabat, 2000.

- Binebine, 2004 : Ahmed-Chouqui Binebine, Dirāsāt fī 'ilm al-makhțūtạt wa al-bahth al-bibliyūghrāfí ( $2^{\mathrm{e}}$ éd. révisée et augmentée), Marrakech, 2004.

- Binebine, 2013 : Ahmed-Chouqui Binebine, Al-Kitāa al- 'arabī al-makhțūt fì shamāl ifrīayā wa-janūb al-șahrā', Londres, 2013.

- BLAIR, 2006 : Sheila S. Blair, Islamic Calligraphy, Édimbourg, 2006.

- BLOOM, 1986 : Jonathan Bloom, "AlMa'mun's Blue Koran? ", dans Revue des Études Islamiques, $\mathrm{n}^{\circ}$ 54, 1986, p. 59-65.

- BLoom, 1989 : Jonathan Bloom, "The Blue Koran: an Early Fatimid Kufic Manuscript from the Maghreb ", dans François Déroche (dir.), Les manuscrits $d u$ Moyen-Orient. Essais de codicologie et de paléographie, actes du colloque (Istanbul, Institut français d'études anatoliennes, 1986), Istanbul/Paris, 1989, p. 95-99.

- Bloom, 2015 : Jonathan Bloom, "The Blue Koran Revisited ", dans Journal of Islamic Manuscripts, vol. 6, $\mathrm{n}^{\text {os }} 2-3,2015$, p. 196-218.

- BNT, 1977-2015: Dār al-Kutub alWațaniyya, Fihris al-makhțūtăt; puis : AlMaktaba al-Wațaniyya, Al-fihris al-'āmm li'l-makhțūtāt, 10 vol., Tunis, 1977-2015.
- Bongianino, 2015 : Umberto Bongianino, "Le manuscrit X 56 sup. (Kitāb Sībawayh) de la Bibliothèque Ambrosienne et les écritures de l'Occident arabe avant la diffusion du mağribī arrondi ", dans JAOUHARI, 2015, p. 5-25.

- Bongianino, 2017 : Umberto Bongianino, "The Origin and Development of Maghribī Round Scripts: Arabic Palaeography in the Islamic West (4th/10th6th/12th Centuries) ", thèse de doctorat, Oxford University, 2017.

- Boujdad MKadem, Nieuwenhuysen, 2012 : Abdelhamid Boujdad Mkadem, Paul Nieuwenhuysen, "Les défis du financement des projets de numérisation des manuscrits : le cas des associations culturelles marocaines ", dans Gazette du Livre Médiéval, vol. 58, $\mathrm{n}^{\circ}$ 1, 2012, p. 69-76. - Bouterfa, 2005 : Saïd Bouterfa, Les manuscrits du Touat, le sud algérien, Méolans-Revel, 2005.

- BRINQUis, CARMen, 2008 : Hidalgo Brinquis, María del Carmen, "Características del papel de los manuscritos hispano-árabes ", dans N. Martínez de Castilla et al. (dir.), Colecciones madrileñas. Transmisiones moriscas: Jornadas sobre manuscritos árabes: actas, actes des journées d'études (Madrid, Facultad de Geografía e Historia de la Universidad Complutense, 2007), Madrid, 2008, p. 171-182.

- BUHLĪ AL-NAYYĀL, 1953 : Muhammad al-Buhlī al-Nayyāl, "Al-maktaba al'atīqa bi-jāmi' 'uqba bi'l-qayrawān ", dans Majallat al-Nadwa al-Tūnisiyya, $\mathrm{n}^{\circ} 1$, 1953, p. 6-16 et 2, 1953, p. 14.

- Buhlī AL-NAYYĀL, 1963 : Muḥammad al-Buhlī al-Nayyāl, Al-maktaba al-āthāriyya bi'l-qayrawān: 'arḍ wa-dalīl, Tunis, 1963.

- BUREsi, 2008 : Pascal Buresi, "Une relique almohade : l'utilisation du Coran de la Grande Mosquée de Cordoue (attribué à 'Uthmān b. 'Affān) ", dans Lieux de cultes : aires votives, temples, églises, mosquées, actes du colloque (Tripoli, IX ${ }^{e}$ colloque international sur l'histoire et l'archéologie de l'Afrique du Nord antique et médiévale, 2005), Paris, 2008, p. 273-280.

- De Carthage à Kairouan..., 1982-1983 : De Carthage à Kairouan, 2000 ans d'art et d'histoire en Tunisie, cat. exp. (Paris, Musée du Petit Palais, 1982-1983), Paris, 1982.

- Chаввоuн, 1956 : Ibrahim Chabbouh, "Sidjill qadīm li-maktabat jāmi " al-Qayrawān ", dans Majallat Ma had alMakhtūtụāt al- 'Arabiyya, vol. 2, n 2, 1956 , p. 339-372.

- Chaвbouh, 1989 : Ibrahim Chabbouh, Min nafā'is Dār al-Kutub al-Wațaniyya, 
I. Al-makhțūt / Chefs d'ouvre de la Bibliothèque nationale de Tunisie, 1. Le manuscrit, Tunis, 1989.

- CheikHa, 2008 : Djomaa Cheikha, Dār al-kutub al-wataniyya, min sūq al- atțārìn ilā rabwat al-tawfĩq, tārīkh hăfil wa mustaqbal zāhir / La Bibliothèque nationale, du souk al-attarine à la colline al-tawfiq, histoire glorieuse et avenir prospère, Tunis, 2008.

- CODERA, 1888 : F. Codera, « Biblioteca de la Mezquita Azzeituna de Tunez", dans Boletin de la Real Academia de la Historia, vol. 13, n 1-3, 1888, p. 26-44.

- DANDEL, 1993 : Élisabeth Dandel, «Ibn Ġațūus : une famille de copistes-enlumineurs à Valence (Espagne) ", dans Histoire de l'Art, n² 24, décembre 1993, p. 13-24.

- DANDel, 1994 : Élisabeth Dandel, " L'enluminure hispano-maghrébine du $\mathrm{VI} / \mathrm{XII}^{\mathrm{e}}$ au IX/XV siècle ", thèse de doctorat, université Paris-Sorbonne, 1994.

- DANDEL, 1999 : Élisabeth Dandel, "À propos d'un coran almohade copié en soixante volumes", dans Serge Lancel (dir.), Afrique du Nord antique et médiévale : numismatique, langues, écritures et arts du livre, spécificité des arts figurés, actes du colloque (Nice, VII ${ }^{\mathrm{e}}$ colloque international réunis dans le cadre du $121^{\mathrm{e}}$ congrès des Sociétés historiques et scientifiques, 1996), Paris, 1999, p. 249-265.

- DÉRoche, 1983 : François Déroche, $\mathrm{Ca}$ talogue des manuscrits arabes. Deuxième partie : manuscrits musulmans. I. Les manuscrits du Coran, I-I. Aux origines de la calligraphie coranique, Paris, 1983.

- Déroche, 1985 : François Déroche, Catalogue des manuscrits arabes. Deuxième partie : manuscrits musulmans, I. Les manuscrits du Coran. I-II. Du Maghreb à l'Insulinde, Paris, 1985.

- Déroche, 1989 : François Déroche, "Les manuscrits arabes datés du III"/ IX siècle ", dans Revue des Études islamiques, $\mathrm{n}^{\text {os }}$ 55-57, 1987-1989, p. 343-380. - Déroche, 1991 : François Déroche, "Deux fragments coraniques maghrébins anciens au musée des Arts Turc et Islamique d'Istanbul ", dans Revue des Études islamiques, $\mathrm{n}^{\circ}$ 59, 1991, p. 229-235.

- DÉROCHe, 1992 : François Déroche, Nasser D. Khalili Collection of Islamic art, I. The Abbasid tradition: Qur'ans of the 8th to the 10th Centuries AD, Londres/Oxford, 1992.

- Déroche, 1994 : François Déroche, "O. Houdas et les écritures maghrébines ", dans Ahmed-Chouqui Binebine (dir.), Le manuscrit arabe et la codicologie, Rabat, 1994, p. 75-81.

- Déroche, 1999 : François Déroche, " Tradition et innovation dans la pratique de l'écriture au Maghreb pendant les IVe/ $\mathrm{X}^{\mathrm{e}}$ et $\mathrm{V}^{\mathrm{e}} / \mathrm{XI}^{\mathrm{e}}$ siècles ", dans Serge Lancel (dir.), Afrique du Nord antique et médiévale : numismatique, langues, écritures et arts $d u$ livre, spécificité des arts figurés, actes du colloque (Nice, VII ${ }^{\text {e }}$ colloque international réunis dans le cadre du $121^{\mathrm{e}}$ congrès des Sociétés historiques et scientifiques, 1996), Paris, 1999, p. 233-247.

- DÉROCHE et al., 2000 : François Déroche et al., Manuel de codicologie des manuscrits en écriture arabe, Paris, 2000.

- Déroche, 2001a : François Déroche, " Cercles et entrelacs. Format et décor des Corans maghrébins médiévaux ", dans Comptes Rendus des Séances de l'Académie des Inscriptions et Belles-Lettres, $145^{\mathrm{e}}$ année, $\mathrm{n}^{\circ} 1$ 1, 2001, p. 593-620.

- DÉRoche, 2001b : François Déroche, "Les emplois du Coran, livre manuscrit ", dans Revue de l'Histoire des Religions, vol. 218, n ${ }^{\circ} 1,2001$, p. 43-63.

- DÉRoche, 2005 : François Déroche, Le Coran, Paris, 2005.

- DÉRoche, 2008 : François Déroche, " Autour de l'inventaire médiéval de la bibliothèque de la mosquée de Kairouan : livres et mosquées au Maghreb ", dans Lieux de cultes : aires votives, temples, églises, mosquées, actes du colloque (Tripoli, $\mathrm{IX}^{\mathrm{e}}$ colloque international sur l'histoire et l'archéologie de l'Afrique du Nord antique et médiévale, 2005), Paris, 2008, p. 247-255.

- DÉROCHE, 2009 : François Déroche, La transmission écrite du coran dans les débuts de l'Islam. Le codex parisino-petropolitanus, Leyde/Boston, 2009.

- Déroche, 2010a : François Déroche, "A Note on the Medieval Inventory of the Manuscripts Kept in the Great Mosque of Kairouan ", dans Robert M. Kerr et Thomas Milo (dir.), Writings and Writing. Investigations in Islamic Text and Script in Honour of Januarius Justus Witkam, Leyde/Boston, 2010, p. 67-86.

- Déroche, 2010b : François Déroche, "Andalusī ou mag̉ribī ibérique ? ", dans Nuria Martinez de Castilla (dir.), Documentos y manuscritos arabes del Occidente musulman medieval, Madrid, 2010, p. 369380.

- Dessus-LAmare, 1938 : Alfred DessusLamare, "Le muṣhaf de la mosquée de Cordoue et son mobilier mécanique ", dans Journal Asiatique, n 230, 1938, p. 551-575.

- D'OtTone, 2013 : Arianna D'Ottone, "Al-hațt al-maghribī et le fragment bilingue latin-arabe Vat. Lat. 12900 : quelques observations ", dans JAOUHARI, 2013, p. 7-18.
- DutTon, 1999 : Yasin Dutton, « Red Dots, Green Dots, Yellow Dots and Blue. Some Reflections on the Vocalisation of Early Qur'anic Manuscripts. Part I ", dans Journal of Qur'anic Studies, vol. 1, $\mathrm{n}^{\circ} 1,1999$, p. 115-140.

- Dutton, 2000 : Yasin Dutton, « Red Dots, Green Dots, Yellow Dots and Blue. Some Reflections on the Vocalisation of Early Qur'anic Manuscripts. Part II ", dans Journal of Qur'anic Studies, vol. 2, $\mathrm{n}^{\circ} 1,2000$, p. 1-24.

- ENNAHID, 2011 : Said Ennahid, «Information and Communication Technologies for the Preservation and Valorization of Manuscript Collections in Morrocco ", dans Graziano Krätli, Ghislaine Lydon (dir.), The Trans-Saharan Book Trade. Manuscript Culture, Arabic Literacy and Intellectual History in Muslim Africa, Leyde/ Boston, 2011, p. 265-289.

- ERGIN, 2008 : Nina Ergin, "The Soundscape of Sixteenth-Century Istanbul Mosques. Architecture and Qur'an Recital ", dans Journal of the Society of Architectural Historians, vol. 67, $\mathrm{n}^{\circ} 2$, juin 2008, p. 204-221.

- ERgin, 2013 : Nina Ergin, "A MultiSensorial Message of the Divine and the Personal. Qur'anic Inscriptions and Recitation in Sixteenth-Century Ottoman Mosques ", dans Mohammad Gharipour et Irvin Cemil Schick (dir.), Calligraphy and Architecture in the Muslim World, Édimbourg, 2013, p. 105-118.

- Espejo, ARIAs, 2008 : Teresa Espejo et Juan Pablo Arias (dir.), El manuscrito andalusí: hacia una denominación de origen/ Al-Makhțūt al-andalusī: al-ittijāh ilā 'alāmat aṣāla, Séville, 2008.

- ESPEJO, ARIAS, 2009 : Teresa Espejo et Juan Pablo Arias, El Coran de Cútar. Una joya del patrimonio escrito andalusí, Séville, 2009.

- EsPejo, Beny, 2008 : Teresa Espejo et Ana Beny, "Protocolo de descripción del manuscrito andalusí ", dans ESPEJO, ARIAS, 2008, p. 87-147.

- Estève, 200 la : Jean-Louis Estève, "Le zigzag dans les papiers arabes : essai d'explication ", dans Gazette du Livre Médiéval, no 38, printemps 2001, p. 40-49.

- Estève, $2001 \mathrm{lb}$ : Jean-Louis Estève, "Observation sur la disposition des vergeures dans les papiers arabo-andalous ", dans Gazette du Livre Médiéval, n 39, automne 2001, p. 48-50.

- Estève, 2003 : Jean-Louis Estève, "Zigzag ou vergeures "raboutées" ? Le cas du ms. Persan 126 de la Bibliothèque nationale de France ", dans Gazette du 
Livre Médiéval, $\mathrm{n}^{\circ} 42$, printemps 2003, p. 47-50.

- EsTÈVE, 2004 : Jean-Louis Estève, "Les vergeures "claires-obscures" des papiers arabes : proposition d'explication ", dans Gazette du Livre Médiéval, $\mathrm{n}^{\circ} 45$, automne 2004, p. 58-63.

- ESTÈVE, 2015 : Jean-Louis Estève, « Relire Oriol Valls i Subirà' ", dans Journal of Islamic Manuscripts, $\mathrm{n}^{\circ}$ 6, 2015, p. 239-259.

- FRASER, KWIATKOWSKI, 2006 : Marcus Fraser, Will Kwiatkowski, Ink and Gold: Islamic Calligraphy, Londres, 2006.

- GACEK, 1989: Adam Gacek, "The Ancient Sijill of Qayrawan ", dans MELA Notes, $\mathrm{n}^{\circ} 46$, hiver 1989, p. 26-29.

- GACEK, 1991 : Adam Gacek, "Arabic Bookmaking and Terminology as Portrayed by Bakr al-Ishbīlī in his Kitāb altaysīr fì șinā at al-tasfìr ", dans Manuscripts of the Middle East, no 5, 1991, p. 106-113. - GEORGE, 2010a : Alain George, The Rise of Islamic Calligraphy, Londres/Berkeley, 2010.

- GEORGE, 2010b : Alain George, "Calligraphy, Colour and Light in the Blue Qur'an ", dans Journal of Qur'anic Studies, vol. 11, no 1, 2010, p. 75-125.

- GeORGE, 2015a : Alain George, "Coloured Dots and the Question of Regional Origins in Early Qur'ans (Part I) ", dans Journal of Qur'anic Studies, vol. 17, $\mathrm{n}^{\circ} \mathrm{l}$, 2015, p. 1-44.

- GEORGE, 2015b : Alain George, "Coloured Dots and the Question of Regional Origins in Early Qur'ans (Part II) ", dans Journal of Qur'anic Studies, vol. 17, n 2, 2015, p. 75-102.

- GLADISS, 2004 : Alamut von Gladiss, "Zur Handschriftenillumination in Marokko ", dans Martina Müller-Wiener et al. (dir.), Al-Andalus und Europa: zwischen Orient und Okzident, Petersberg, 2004, p. 325-330.

- GONZALES GARCIA, 2014 : Sonsoles Gonzáles García, " Estudio de las encuadernaciones originales de la Colección de manuscritos árabes de la Biblioteca de la Escuela de Estudios Arabes de Granada ", thèse de doctorat, Universidad de Grenada, 2014.

- GUINEAU, 2000 : Bernard Guineau, « Les matériaux de la couleur dans les manuscrits maghrébins ( $\mathrm{VI}^{\mathrm{e}}-\mathrm{IX}^{\mathrm{e}} \mathrm{s}$.) : éléments d'identification et de comparaison ", dans DÉROCHE et al., 2000, p. 145-167.

- HENDRICKSON, 2008 : Jocelyn Hendrickson, "A guide to Arabic Manuscript Libraries in Morocco, with Notes on Tunisia, Algeria, Egypt, and Spain ", dans MELA Notes, $\mathrm{n}^{\circ} 81,2008$, p. 15-88.
- Houdas, 1886 : Octave Houdas, « Essai sur l'écriture maghrébine ", dans Nouveaux Mélanges Orientaux, Paris, 1886, p. 85-112.

- HumberT, 2002 : Geneviève Humbert, "Introduction ", dans Revue des Mondes Musulmans et de la Méditerranée, $\mathrm{n}^{\circ}$ 99-100, 2002, p. 7-14 [en ligne, URL : http:// remmm.revues.org/document2916.html (consulté le 9 juin 2017)].

- Islamic Seals Database, 2017 : Chester Beatty Library, Islamic Seals Database, base de données en ligne : http://www.cbl.ie/ islamicseals/Home.aspx.

- Itinéraire du savoir en Tunisie..., 1995 : Itinéraire du savoir en Tunisie. Les temps forts de l'histoire tunisienne, Hassen Annabi, Mounira Chapoutot-Remadi, Samia Kamarti (dir.), cat. exp. (Paris, Institut du Monde Arabe, 1995), Tunis/Paris, 1995.

- JAOUhARI, 2013a : Mustapha Jaouhari (dir.), Les écritures des manuscrits de l'Occident musulman, actes de la journée d'études (Rabat, Les rencontres du CJB $\mathrm{n}^{\circ}$ 5, 2012), Rabat, 2013.

- JAOUHARI, 2013b : Mustapha Jaouhari, "Quelques types du maǵribī des XI ${ }^{\mathrm{e}}$ et $\mathrm{XII}^{\mathrm{e}}$ siècles : prémisses d'une enquête en cours ", dans JAOUHARI, 2013, p. 19-30.

- JAOUHARI, 2015 : Mustapha Jaouhari (dir.), Paléographie des écritures arabes d'alAndalus, du Maghreb et de l'Afrique subsaharienne, actes de la journée d'études (Rabat, Les rencontres du CJB $n^{\circ} 6$, 2013), Rabat, 2015 [en ligne, URL : http://www.cjb.ma/images/2015/pdf/ Rencontres_du_CJB_n_6.pdf (consulté le 6 décembe 2017)].

- KelLer, 1985 : Adriaan Keller, « Étude codicologique comparée des manuscrits ibériques médiévaux ", dans Gazette du livre médiéval, nº 7, automne 1985, p. 15-17.

- LÉVI-PROVENÇAL, 1934 : Évariste LéviProvençal, " Un manuscrit de la bibliothèque du calife al-Ḥakam II ", dans Hespéris, vol. 18, n 2, 1934, p. 198-200.

- LINGS, 1961 : Martin Lings, "Andalusian Qorans ", dans The British Museum Quarterly, no 24, 1961, p. 94-96, pl. 30-32. - LuCCIONI, 1955 : Joseph Luccioni, "Les bibliothèques habous au Maroc ", dans Bulletin Économique et Social du Maroc, vol. 66, n 19, septembre 1955, p. 233-245.

- MANŪNĪ, 1991 : Muhḥammad alManūn̄̄, Tārīkh al-wirāqa al-maghribiyya min al-' 'aṣr al-wasịt ilā al-fatra al-mu'āṣira, Rabat, 1991.

- MANŪNĪ, 2005 : Muhammad ibn 'Abd al-Hādī al-Manūnī, Dūr al-kutub fì māộ̀ almaghrib, Rabat, 2005.
- Manuscrits arabes..., 1990 : Manuscrits arabes en Occident musulman : état des collections et perspectives de la recherche, Casablanca, 1990, p. 95-112.

- MARÇAIS, POINSSOT, 1952 : Georges Marçais, Louis Poinssot, Objets kairouanais, IX $X^{e}$ au XIII siècle : reliures, verreries, cuivres et bronzes, bijoux, Tunis/Paris, 1952. - Maroc médiéval..., 2014-2015 : Le Maroc médiéval : un empire de l'Afrique à l'Espagne, Yannick Lintz, Claire Déléry et Bulle Tuil Leonetti (dir.), cat. exp. (Paris, musée du Louvre, 2014-2015; Rabat, Musée Mohammed VI, 2015), Paris, 2014.

- MARTIN, 1912 : Frederick Robert Martin, The Miniature Painting and Painters of Persia, India and Turkey from the 8th to the 18th Century, Londres, 1912.

- Mehrez, 1955 : Jamāl Muhammad Mehrez, "Muṣhaf mudhahhab min al'așr al-gharnāțī ", dans Revista del Instituto Egipcio de Estudios Islamicos en madrid, vol. 3, no 1, 1955, p. 141-147.

- Mzoughi, Ben Hamada, 1994 : Hassine Mzoughi, Jamel Ben Hamada, Makhțūtātunā al-maghāribiyya : namādhidj wa 'ayyināt / Spécimens de manuscrits maghrébins, Tunis, 1994.

- Neumeier, 2008 : Emily Neumeier, "The Blue Koran: Debating an Early Koranic Manuscript ", dans Elements: Boston College Undergraduate Research Journal, $\mathrm{n}^{\circ} 1,2006$, p. 11-19.

- RAMMAH, 2008a : Mourad Rammah, Le Musée des arts islamiques de Raqqāda (Kairouan), Tunis, 2008.

- RAMMAH, 2008b : Mourad Rammah, " Maktabat al-qayrawān al- 'atīqa wa subul șiyānatihā ", dans Al-Hayāt alThaqāiyya, avril 2008, p. 120-128.

- RAMMAH, 2009 : Mourad Rammah, Trésors de Kairouan/Treasures of Kairouan/ Kunūz al-qayrawān, Kairouan, 2009.

- RICARD, 1933 : Prosper Ricard, "Reliures marocaines du XIII siècle ", dans Hespéris, vol. 17, nº 2, 1933, p. 109-127. - RICARD, 1934 : Prosper Ricard, "Sur un type de reliure des temps almohades ", dans Ars Islamica, $\mathrm{n}^{\circ}$ 1, 1934, p. 74-79.

- RodRiguez DiAz, 2011 : Elena E. Rodríguez Díaz, "Los manuscritos mozárabes : una encrucijada de culturas " dans Matias Maser, Klaus Herbers (dir.), Die Mozaraber. Definitonen und Perspektiven der Forschung, Münster, 2011, p. 75-102.

- Roger, SERguini, DÉRoche, 2004 : Patricia Roger, Malika Serguini et François Déroche, "Les matériaux de la couleur dans les manuscrits arabes de l'Occident musulman. Recherches sur la collection 
de la Bibliothèque générale et archives de Rabat et de la Bibliothèque nationale de France ", dans Comptes-rendus des séances de l'Académie des Inscriptions et Belles-Lettres, avril-juin 2004, p. 799-830.

- ROPER, 1991- : Geoffrey Roper, World Survey of Islamic Manuscripts, Londres, 1991-.

- SCheele, 2011 : Judith Scheele, "Coming to Terms with Tradition. Manuscript Conservation in Contemporary Algeria ", dans Graziano Krätli, Ghislaine Lydon (dir.), The Trans-Saharan Book Trade. Manuscript Culture, Arabic Literacy and Intellectual History in Muslim Africa, Leyde/ Boston, 2011, p. 291-318.

- SCHePer, 2014 : Karin Scheper, The Technique of Islamic Bookbinding. Methods, Materials and Regional Varieties, Leyde/ Boston, 2014.

- SiJELMASSI, 1987 : Mohamed Sijelmassi, Les enluminures des manuscrits royaux $d u$ Maroc (Bibliothèque al-Hassania), Courbevoie, 1987.

- Splendeurs de l'écriture au Maroc..., 2017 : Splendeurs de l'écriture au Maroc: manuscrits rares et inédits/Rawā' 'i al-kitāba bi'l-maghrib: makhțuttāt nādira, cat. exp. (Paris, Institut du Monde Arabe, 2017), Rabat/ Paris, 2017.

- Stanley, 1995 : Tim Stanley, The Qur'an and Calligraphy. A Selection of Fine Manuscript Material, Londres, 1995.

- SUFYĀNĪ, 1925 : Aḥmad b. Muḥammad al-Sufyānī, Șinā at tasfìr al-kutub wa hall al-dhahab/L'Art de la reliure et de la dorure, Prosper Ricard (éd.), Paris, 1925 (2 édition).

- TABbAA, 1991 : Yasser Tabbaa, "The Transformation of Arabic Writing. I. Qur'anic Calligraphy ", dans Ars Orientalis, $\mathrm{n}^{\circ} 21,1991$, p. 119-148.

- Tunisie : du christianisme à l'Islam..., 2001 : Tunisie : du christianisme à l'Islam, $I V^{e}$-XIV siècle, Christian Landes, Habib Hassen, Soumicha Chennoufi et. al., cat. exp. (Lattes, Musée Archéologique HenriPrades, 2001), Lattes, 2001.

- 'Umdat al-Kuttāb... : 'Umdat al-kuttāa wa 'uddat dhawi al-albāb, 'Abd al-Sattār alḤalwajī et 'Alī 'Abd al-Muhsin Zakī (éd.), dans Majallat Ma'had al-Makhtūtāat al'Arabiyya, vol. 17, n' 1, 1971, p. 43-172.

- VALLS I SUBIRÀ, 1978 : Oriol Valls I Subirà, The History of Paper in Spain, Madrid, 1978.

- VAN Den Boogert, 1989 : Nico Van den Boogert, "Some Notes on Maghribī Script ", dans Manuscripts of the Middle East, no 4, 1989, p. 30-43.
- VAN Koningsveld, 1976 : Peter Sjoerd Van Koningsveld, The Latin-Arabic Glossary of the Leiden University Library. A Contribution to the Study of Mozarabic Manuscripts and Literature, Leyde, 1976.

- Viguera Molins, Fanjul García, 2016 : María Jesús Viguera Molins, Serafín Fanjul García, Los manuscritos árabes en España: su historia y la Historia dicurso leído el día 28 de febrero de 2016 en el acto de su recepción pública por la Excma. Sra. $D^{a}$ María Jesús Viguera Molins y contestación por el Excmo. Sr. Don Serafín Fanjul García, Madrid, 2016.

- VOGUET, 2003 : Élise Voguet, "L'inventaire des manuscrits de la bibliothèque de la Grande Mosquée de Kairouan (693/1293-4) : une contribution à l'histoire du mâlikisme kairouannais ", dans Arabica, vol. 50, n 4, 2003, p. 532-544.

- ZADEH, 2008 : Travis Zadeh, "From Drops of Blood. Charisma and Political Legitimacy in the Translatio of the 'Uthmānic Codex of al-Andalus ", dans Journal of Arabic Literature, $\mathrm{n}^{\circ} 39,2008$, p. 321-346.

- Zaytūniyya..., 1884 : Daftar al-maktaba al-Zaytūniyya, Tunis, 1301/1884. 